Originalveröffentlichung in: Hans Beck, Peter Scholz, Uwe Walter (Hg.), Die Macht der Wenigen.

Aristokratische Herrschaftspraxis, Kommunikation und, edler' Lebensstil in der Antike und Frühen Neuzeit (Historische Zeitschrift Beihefte N.F. 47), München 2008, S. 71-99

\title{
Die ,Macht der Wenigen' in den hellenistischen Städten
}

\section{Von \\ Peter Scholz}

Der vorliegende Beitrag beschränkt sich darauf, die Merkmale zu umreißen, die für die informelle Herrschaft der ,Wenigen' in den hellenistischen Städten konstitutiv waren. Dies geschieht nicht zuletzt aus dem Grund, um einen epochenübergreifenden Vergleich zu erleichtern. Dabei werde ich versuchen, das öffentliche Wirken der städtischen Führungsschicht in hellenistischer Zeit in seiner ganzen Bandbreite darzustellen - das heißt konkret: diese, Wenigen' als Redner und Inhaber politischer, militärischer und religiöser Ämter, zugleich aber auch als Vermittler und Spender materieller, Wohltaten und politischer und rechtlicher Privilegien vorzustellen. Damit dies nicht im Abstrakten bleibt, sollen einige hellenistische Ehrendekrete, die unter der großen Vielzahl der erhaltenen repräsentativ erscheinen, dazu dienen, eine Anschauung von der Vielfalt des öffentlichen Wirkens dieser Männer zu gewinnen.

Der Beitrag gliedert sich dabei in sechs Teile: Zunächst werden anhand der Bezeichnungen für Aristokraten und Oligarchen die aristokratischen Traditionsbestände aus archaischer und klassischer Zeit kurz umrissen, dann werde ich auf das generelle Verhältnis zwischen städtischer Führungsschicht und Demos im Hellenismus eingehen, im dritten Teil die Tendenzen zur Exklusivierung und Aristokratisierung der Oberschicht im 2. und 1.Jahrhundert v. Chr. beschreiben, im vierten anhand von Ehrendekreten einige führende Männer und Familien in den hellenistischen Städten vorstellen, im fünften einen Blick auf den Bildungsgang der Honoratiorensöhne werfen und am Ende ein kurzes Resümee ziehen.

\section{Bezeichnungen für Aristokraten und Oligarchen in archaischer und klassischer Zeit}

In den literarischen und inschriftlichen Quellen des 6. und 5.Jahrhunderts v. Chr. werden Aristokraten mit ganz unterschiedlichen Begriffen als führende Männer gekennzeichnet: uneinheitlich werden sie als die „Wenigen“

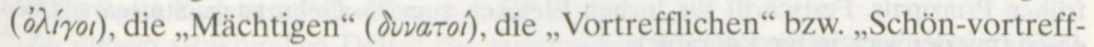

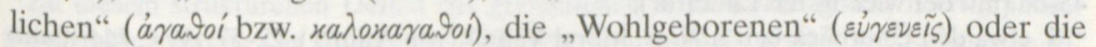

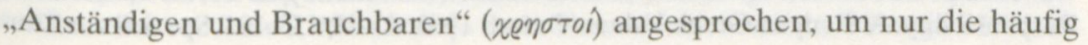


verwendeten Titulierungen anzuführen. ${ }^{1}$ Unterteilt man diese kurze Liste in Fremd- und Selbstbezeichnungen, so heben die Fremdbezeichnungen entweder bloß die quantitative Größe der Gruppe der Herrschenden hervor ( $\dot{o} \lambda$ í$\left.^{\prime} \iota \iota\right)$ oder verweisen auf die überlegenen finanziellen Möglichkeiten und Machtmittel dieser Familien ( $\delta$ vvatoi). Demgegenüber akzentuieren die Selbstbezeichnungen andere Merkmale: etwa das mit der Geburt bereits erworbene Ansehen bzw. die Familientradition ( $\varepsilon \dot{v} \gamma \varepsilon v \varepsilon \tilde{\zeta}$ ) oder die aus dem Aufwachsen in diesem Milieu erworbene soziale und moralische Exzellenz wie überhaupt generell herausragende Fähigkeiten, die sie als besonders nützlich erschei-

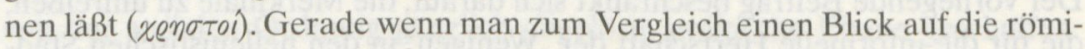
sche Senatsaristokratie wirft ${ }^{2}$, wird sofort augenfällig, daß in archaischer Zeit innerhalb - und auch außerhalb - der Führungsschicht kein grundsätzlicher Konsens darüber bestand, auf welchen Qualitäten der laut propagierte Führungsanspruch eigentlich beruhen sollte. So weist bereits die Uneinheitlichkeit der Terminologie auf die Labilität des Status der Aristokraten hin, genauer gesagt, auf deren mangelnde Einbindung in eine politische Gemeinschaft, was das Fehlen eines entsprechenden Bindungswillens einschloß, und den Mangel an jeglicher inneren Kohärenz als soziale Gruppe. Die griechischen Aristokraten waren weder willens noch imstande, gegen die zumindest formal und in den Institutionen auch in hellenistischer Zeit noch nach wie vor bestehende Herrschaft des Volkes eine einheitliche Selbstbezeichnung für sich zu entwickeln und sich so auch machtpolitisch als Kollektiv gegenüber dem Demos durchzusetzen. Die in den Quellen genannten Begriffe geben jedoch hinreichend darüber Auskunft, worauf der Führungsanspruch der Aristokraten gründete: Reichtum, Familientradition, Muße zu Krieg, Politik und Sport, militärische Fähigkeiten, auch Redegewalt und intellektuelle Bildung.

Im Gegensatz zur archaischen Zeit, wo Autoren wie Homer, Hesiod, Theognis, Archilochos, Tyrtaios, Xenophanes, Solon, Pindar und Bakchylides vorliegen, die unmittelbaren Einblick in das Wertesystem griechischer Aristokraten ${ }^{3}$ gewähren, fehlen solche Quellen für den Hellenismus weitge-

$1 \mathrm{Zu}$ den verschiedenen begrifflichen Umschreibungen der sozialen und politischen Führungsschichten: Arthur W. H. Adkins, Moral Values and Political Behaviour in Ancient Greece. From Homer to the End of the Fifth Century. London 1972, 58-75.

2 S. hierzu ausführlich den Beitrag von Hans Beck in diesem Band. Zur Einführung: Jochen Bleicken, Die Nobilität der römischen Republik, in: Gymnasium 88, 1981, 236-253 (= ders., Gesammelte Schriften. Bd.1. Stuttgart 1998, 466-483). Die neueren Diskussionen hat jüngst zusammengefaßt: Frank Goldmann, Nobilitas als Status und Gruppe. Überlegungen zum Nobilitätsbegriff der römischen Republik, in: Jörg Spielvogel (Hrsg.), Res publica reperta. Zur Verfassung und Gesellschaft der römischen Republik und des frühen Prinzipats. Festschrift für Jochen Bleicken zum 75. Geburtstag. Stuttgart 2002, 45-66 (mit der wichtigsten Literatur).

3 S. etwa den Überblick bei: Adkins, Moral Values (wie Anm.1), 22-57; ders., Merit and Responsibility. A Study in Greek Values. Oxford 1960, 60-85, 153-194. Speziell zur Titu- 
hend. Als Ersatz für diese stehen jedoch zahlreiche Ehrendekrete und Grabepigramme hochgestellter Bürger zur Verfügung, aus denen wir das Selbstverständnis, die Werte, Ansprüche, Erwartungen und Legitimierungsstrategien durch Interpretation gewinnen können. Sie belegen eindrücklich, daß die in archaischer Zeit ausgeprägten Überlegenheitsmerkmale auch in hellenistischer Zeit bewahrt blieben und durchaus noch lebendig waren: Kraft und Geschicklichkeit, Schönheit und athletische Erfolge, Kriegsruhm und Richterkompetenz - all das, was individueller Tatkraft entsprang und besondere Vorzüglichkeit in Aussehen, in Wort und Tat bewies, war nach wie vor von großer Bedeutung. So sehr jedoch die Adligen auf zahlreichen kulturellen Feldern zweifelsohne brillierten, so wenig erwiesen sie sich imstande, zu einer politischen Vergemeinschaftung mit den Standesgenossen zu finden. Den Aristokraten gelang es nicht, in politicis Geschlossenheit und entsprechend soziale Stoßkraft zu entwickeln: Das Feld, auf dem die Aristokraten in archaischer und klassischer Zeit hauptsächlich miteinander in Konkurrenz traten, war (noch) nicht überwiegend die Politik, sondern vor allem die Muße. Die gemeinsame Identität der Aristokraten beruhte auf der Teilhabe an einem bestimmten Normengefüge, an einem bestimmten Lebensstil und an gemeinsamen kulturellen Praktiken - hier ist etwa auf das Institut des Symposions und die Rang und Prestige begründende Teilnahme an panhellenischen Spielen zu verweisen. ${ }^{4}$ Die Identität der griechischen Aristokraten war somit weniger politisch als vielmehr überwiegend sozial und kulturell bestimmt: Auf lokaler Ebene hatten sie keine gemeinsamen Aufgaben für sich gefunden, keine Form der Selbstverpflichtung entwickelt und keine Institutionalisierung der Herrschaft als Gruppe betrieben. ${ }^{5}$ In der Formierungsphase der Polis waren sie nur sehr schwach in diese eingebunden gewesen. ${ }^{6}$ Weniger als Teilhaber als vielmehr als Bedrohung waren sie anfangs

lierung vornehmer Männer im 5. und 4.Jh. v. Chr. als „schön-vortreffliche Männer" s. die umfassende Studie von: Félix Bourriot, Kalos Kagathos - Kalokagathia I/II. Hildesheim/ Zürich/New York 1995.

${ }^{4}$ Die einzelnen Elemente des Lebensstils aristokratischer Muße, mit der diese soziale Vorrangstellung gegenüber dem einfachen Volk gerechtfertigt wurde, werden eingehend erörtert bei Elke Stein-Hölkeskamp, Adelskultur und Polisgesellschaft. Studien zum griechischen Adel in archaischer und klassischer Zeit. Stuttgart 1989 (2., erw. Aufl. 2008); vgl. P. A. L. Grenhalgh, Aristocracy and its Advocates in Archaic Greece, in: G \& R 19, 1972, 190-207; Nigel J. Nicholson, Aristocracy and Athletics in Archaic and Classical Greece. Cambridge 2005.

${ }^{5}$ Entsprechend wurden erst im 5.Jh. v. Chr. in Athen der Begriff und die Vorstellung von einer ,Aristokratie' geläufig - als eine Bezeichnung, mit der man sich gegenüber den Ansprüchen des Demos zur Wehr setzte: Emilio Gabba, La concezione antica di aristocrazia, in: RAL 6, 1995, 461-468. - Vgl. insgesamt den Beitrag von Winfried Schmitz in diesem Band, auch zum Folgenden.

${ }^{6} \mathrm{Zu}$ diesem strukturellen Defizit der griechischen Aristokratie immer noch grundlegend: Alfred Heuss, Die archaische Zeit Griechenlands als geschichtliche Epoche, in: Antike und Abendland 2, 1946, 26ff. [= ders., Gesammelte Schriften I. Stuttgart 1995, 2- 
empfunden worden. Dies hatte sich erst im 5. und 4. Jahrhundert v. Chr. entscheidend verändert: Erst seit dieser Zeit hatten einzelne Aristokraten die Politik für sich als zentrales Feld des Kampfes um Ehre und Ruhm entdeckt. Notgedrungen und mangels einer Alternative fügten sie sich in die demokratischen Ordnungen ein. ${ }^{7}$ Unzufriedenheit herrschte bei den vermögenden und vornehmen Familien vor allem wegen der hohen finanziellen Belastungen, die ihnen die Bürgerschaft auferlegte. Für viele Aristokraten war insbesondere schwer zu verwinden, $\mathrm{da} ß$ sie sich in den Versammlungen und vor den Gerichten dem Willen der Masse der einfachen Bürger, also dem Abstimmungsverhalten der mittellosen Bauern, Tagelöhner und einfachen Handwerker, beugen und an jenen ihre politischen Vorstellungen ausrichten mußten. Gleichwohl mußte bekanntlich selbst ein Anhänger oligarchischer Ideen wie der sogenannten „Alte Oligarch“ neidvoll die prinzipielle Klugheit des Demos sowie die schwer zu erschütternde Stabilität des demokratischen Herrschaftssystems anerkennen - und damit indirekt auch die Schwäche der vermögenden, Leiturgie leistenden Oberschicht. Zu Beginn seines Pamphlets bemerkt er geradezu resignierend: „Alle Ämter, die der Gesamtheit des Volkes Segen ( $\sigma \omega \tau \eta \varrho i ́ a)$ bringen, wenn sie in guten Händen sind, und Gefahr (xivouvos), wenn in schlechten - die verlangt das Volk nicht im mindesten selbst zu besetzen: Weder die Strategen noch die Reiterführer glauben sie sich durch das Losprinzip besetzen zu müssen; denn sehr gut versteht es das Volk, daß es größeren Nutzen davon hat, wenn es nicht selber diese Ämter verwaltet, sondern die Vermögendsten sie verwalten läßt."8 Angesichts dieser Verhältnisse verwundert es nicht, daß ein Teil der Oberschicht nach Bündnispartnern im Inneren wie Äußeren wie überhaupt nach Möglichkeiten Ausschau hielt, um die Volksherrschaft zu stürzen. Dementsprechend waren innere Unruhen, Bürgerkriege und Verfassungswechsel in den griechi-

38]. S. auch: Elke Stein-Hölkeskamp, Adel und Volk bei Theognis, in: Walter Eder/KarlJoachim Hölkeskamp (Hrsg.), Volk und Verfassung im vorhellenistischen Griechenland. Stuttgart 1997, 21-35; Karl-Wilhelm Welwei, Adel und Demos in der frühen Polis, in: Gymnasium 88, 1981, 1-23. Zur Konstituierung der Bürgergemeinschaft s. Uwe Walter, An der Polis teilhaben. Bürgerstaat und Zugehörigkeit im Archaischen Griechenland. Stuttgart 1993.

7 Zu diesem Komplex s. jetzt umfassend: Christian Mann, Der Demagoge und das Volk. Zur politischen Kommunikation im Athen des 5. Jahrhunderts v. Chr. Berlin 2007. Zu den Wertvorstellungen s. neuerdings: Gabriel Herman, Morality and Behaviour in Democratic Athens. A Social History. Cambridge 2006.

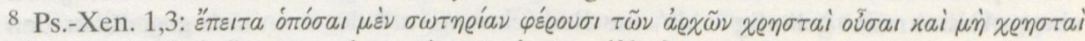

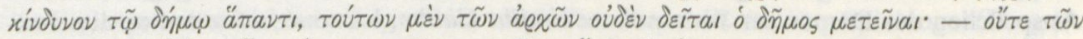

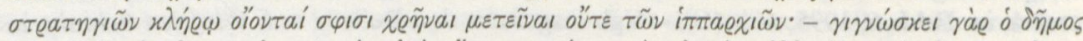

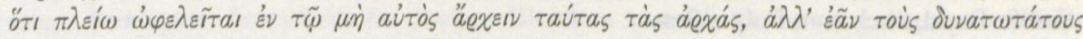
äexsıv. Zur Stelle: Hartvig Frisch, The Constitution of Athenians. Kopenhagen 1942, 192195; Robin Osborne, The Old Oligarch. Pseudo-Xenophon's Constitution of Athens. 2. Aufl. London 2004. 
schen Städten ein endemisches, weil strukturell ungelöstes Problem. ${ }^{9}$ Die griechischen Aristokraten waren weder willens noch imstande, gegen die zumindest formal und in den Institutionen auch in hellenistischer Zeit noch nach wie vor bestehende Herrschaft des Volkes eine einheitliche Selbstbezeichnung für sich zu entwickeln und sich so auch machtpolitisch als Kollektiv gegenüber dem Demos durchzusetzen.

Die uns noch erhaltenen Bürgereide sowie die gegen die Etablierung einer Tyrannis oder Oligarchie gerichteten Beschlüsse aus dem 4. und 3. Jahrhundert v. Chr. bezeugen ihrerseits wiederum die große Furcht der Demokra-

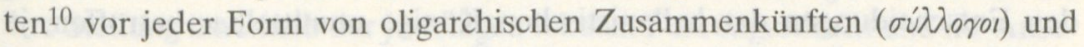
Verschwörungen ( $\sigma \nu \nu \mu \sigma \sigma i a \iota)$. Jedoch bereits der Umstand, daß die Oligarchen offenkundig keinen anderen Begriff als Oligarchie für sich fanden - in einem Beschluß aus Erythrai ist von ,den an der Herrschaft der Wenigen

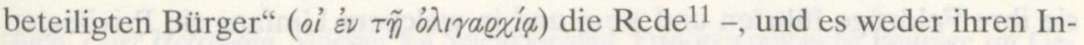
tentionen entsprach noch faktisch gelang, eigene politische Institutionen zu schaffen, weist auf den notwendig ephemeren Charakter der meisten dieser Herrschaften. Die Oligarchien waren nicht mehr als bloße Interessen- und Zweckgemeinschaften, die nicht grundsätzlich darauf aus waren, die Herrschafts- und Verfahrensweisen sowie die Ämter und die bestehenden politischen Gremien zu ändern. Vielmehr hatten die oligarchischen Umstürze in der Regel drei Dinge zum Ziel: den Kreis der Vollbürger drastisch zu redu-

9 Dieses Strukturproblem der griechischen Polis hat zum ersten Mal grundlegend untersucht und dessen Bedeutsamkeit für die Geschichte der Städte herausgestellt: HansJoachim Gehrke, Stasis. Untersuchungen zu den inneren Kriegen in den griechischen Staaten des 5. und 4. Jahrhunderts v. Chr. München 1985.

${ }^{10}$ Durch verschiedene gesetzliche Regelungen versuchte man vielerorts die Herrschaft eines Einzelnen grundsätzlich auszuschließen. Dies ist bezeugt in Athen $336 \mathrm{v}$. Chr. (SEG 12,87 = Epigraphica 27, 1965, 110ff.); Eresos 332 v. Chr. (IG XII 2,526 = OGIS 8), in Ilion zu Beginn des 3. Jh.s v. Chr. (I.v.Ilion 25 = OGIS 218 = HGI III 337). Entsprechend ausgiebig wurden Bürger, die einen solchen Umsturz verhinderten oder maßgeblich zum Sturz einer Tyrannenherrschaft beitrugen, geehrt und überhöht: in Erythrai (I.v.Erythrai II 503, Z. 2 ff. $=$ Syll $^{3}{ }^{2} 284=$ HGI III 338), in Priene (I. Priene 4, Z. $49 \mathrm{ff}$.), im lykischen Araxa (SEG 18, $570=$ HGI III 479, Z. $25 \mathrm{ff} .41 \mathrm{ff}$.) oder auch im Bürgereid von Chersonesos auf der Krim (Syll. ${ }^{3} 360=$ IOSPE I² 401 = HGI III 339; vgl. auch die im Bürgereid des kretischen Itanos erwähnte Versammlung und Verschwörung zum Schaden der Stadt: Syll. ${ }^{3}$ 526= SGDI 5058 = HGI III 439). Überspitzt formuliert könnte man daraus schlieBen, daß der historische Ausgangspunkt und das erste Anliegen der demokratischen Herrschaften in dieser rein negativen, politischen Zielsetzung bestand. Bezeichend ist, daß die Bürger nicht nur einen Eid auf die Demokratie abzulegen, sondern auch ausdrücklich zu erklären hatten, in keiner Weise eine Tyrannis anzustreben, wie beispielsweise in Kos um 205/01 v. Chr. (Staatsverträge III Nr.545, Z. 21 ff.). Zum institutionellen Profil der hellenistischen Städte s. die grundlegenden Untersuchungen von Philippe Gauthier, Les cités hellénistiques, in: Mogens H. Hansen (Ed.), The Ancient Greek CityState. Kopenhagen 1993, 211-231.

${ }^{11}$ Syll. $^{3} 284$ (= IvErythrai II 503 = HGI III 338), Z. 2-3; vgl. I.v.Ilion 25 (= HGI III 337), Z. $19 \mathrm{f}$. 
zieren, die Kompetenzen des Rates gegenüber derjenigen der Volksversammlung zu erweitern und die Vermögenden von den ihnen vom Demos auferlegten finanziellen Bürden zu befreien. ${ }^{12}$

\section{Führungsschicht und Demos in hellenistischer Zeit}

Am Ausgang des 4. Jahrhunderts v. Chr. hatten sich die politischen Rahmenbedingungen nochmals erheblich verändert: Die Städte waren nunmehr von den Entscheidungen der hellenistischen Könige unmittelbar betroffen, ja von diesen geradezu abhängig geworden. ${ }^{13}$ Die neuen Herrscher betrachteten das von ihnen gewonnene, beherrschte oder ererbte Territorium als persönlichen Besitz; und so oblag es ihrem Willen und ihren Plänen, wo und wie sie ihre Feldzüge führten und wem und in welchem Umfang sie Privilegien oder Geschenke zukommen ließen. Die Steuerbelastungen und Einquartierungen ihrer Heere bestimmten das politische wie das alltägliche Leben vieler kleinerer Städte in Griechenland und Kleinasien. Daraus ergab sich zwangsläufig, daß die Aufnahme und Pflege der Beziehung zu dem jeweiligen Herrscherhaus von erheblicher, wenn nicht (über-)lebenswichtiger Bedeutung für die Städte war. ${ }^{14}$ Zwangsläufig gewannen diejenigen innerhalb

$12 \mathrm{Zu}$ den Ausnahmesituationen von 411 und vor allem 404/03 v. Chr. in der Geschichte der athenischen Demokratie s. eingehend (mit weiterführender Literatur) György Németh, Kritias und die Dreißig Tyrannen. Stuttgart 2006; Gustav A. Lehmann, Oligarchische Herrschaft im klassischen Athen. Paderborn 1997, 27-29, 48-54; Peter J. Rhodes, A Commentary on the Aristotelian Athenaion politeia. 2. Aufl. Oxford 1993, 415-480. Allgemein zum Phänomen s. neuerdings auch: Monika Bernett, Antike und moderne Oligarchien, in: Christian Ronning (Hrsg.), Einblicke in die Antike. Orte - Praktiken - Strukturen. München 2006, 23-55. Speziell zur athenischen ,Aristokratie': Paul McKendrick, The Athenian Aristocracy 399 to 31 B.C. Cambridge, Mass. 1969.

13 Zum hellenistischen Königtum: Christian Habicht, The Hellenistic Monarchies. Selected Papers. Ann Arbor 2006; Gregor Weber, Antike Monarchie. Hellenistisches Königtum und römischer Prinzipat. München 2008.

14 Dies ist etwa ein Ergebnis der umfassenden Untersuchung des euergetischen Wirkens der hellenistischen Könige: Klaus Bringmann, Geben und Nehmen. Monarchische Wohltätigkeit und Selbstdarstellung im Zeitalter des Hellenismus. Mit einem numismatischen Beitrag von Hans-Christoph Noeske. Berlin 2000 (mit der Rezension von Philippe Gauthier, in: Gnomon 76, 2004, 40-45); ders., Grain, Timber and Money. Hellenistic Kings, Finance, Buildings and Foundation in Greek Cities, in: Z. H. Archibald u. a. (Eds.), Hellenistic Economies. London/New York 2001, 205-214; ders./Hans von Steuben, Schenkungen hellenistischer Herrscher an griechische Städte und Heiligtümer. T. 1: Zeugnisse und Kommentare. Berlin 1995. Zu den Beziehungen der Städte zu den Herrschern: Ivana Savalli-Lestrade, Les Philoi royaux dans l'Asie hellénistique. Paris/Genf 1998; vgl. ansonsten das klassische Werk von Christian Habicht, Gottmenschentum und griechische Städte. München 1970; ders., Die Rolle der Könige gegenüber Städten und Bünden, in: Michel Christol/Olivier Masson (Eds.), Actes du Xe congrès international d'épigraphie grecque et latine. Paris 1997, 161-168; Richard A. Billows, Cities, in: Andrew Erskine (Ed.), A Companion to the Hellenistic World. Oxford 2003, 196-215. Zur Politik einzelner Monar- 
der städtischen Führungsschicht an Macht und Einfluß, die über Kontakte oder gar nähere freundschaftliche Beziehungen zu den Königshöfen verfügten. Ein mehr oder weniger enges Freundschaftsverhältnis ( $\varphi$ i $\lambda i ́ a)$, oder vielleicht präziser gesagt: die politische Verbundenheit oder sogar persönliche Verpflichtung gegenüber einem Herrscher erlaubte es einem Politiker, zum beiderseitigen Vorteil zwischen Stadt und König, oder später, zwischen römischen Magistraten oder dem Senat und der Heimatpolis zu vermitteln. ${ }^{15}$

Durch diese diplomatischen Dienste trugen viele „Freunde der Könige“16 ganz außerordentlich zum Wohl ihrer Heimatstädte bei; zugleich stärkten sie ihre Stellung innerhalb der jeweiligen lokalen Führungsschicht und ihr Ansehen in der Bürgerschaft nachhaltig. Als besonders prominente Beispiele lassen sich hierzu anführen: Kallias von Sphettos am Hof der ersten Ptolemäer ${ }^{17}$,

chien: Peter Herrmann, Milesier am Seleukidenhof. Prosopographische Beiträge zur Geschichte Milets im 2. Jhdt. v. Chr., in: Chiron 17, 1987, 171-192; John Ma, Antiochos III and the Cities of Western Asia Minor. 2. Aufl. Oxford 2003; Ivana Savalli Lestrade, Les Attalides et les cités grecques d'Asie Mineure au $\mathrm{II}^{\mathrm{e}}$ siècle a.C., in: Alain Bresson/Raymond Descat (Eds.), Les cités d'Asie Mineure occidentale au II ${ }^{\mathrm{e}}$ siècle. Bordeaux 2001, 77-91. Zu den Schwierigkeiten Roms, dieses Erbe der Könige anzutreten: Rainer Bernhardt, Rom und die griechischen Städte des hellenistischen Ostens (3.-1. Jahrhundert v. Chr.). München 1998; Jean-Louis Ferrary, Rome et les cités grecques d'Asie Mineure au II ${ }^{\mathrm{e}}$ siècle, in: Bresson/Descat (Eds.), Les cités d'Asie Mineure occidentale, 93-106.

15 Aufgrund eines derartigen Vertrauensverhältnisses werden die städtischen Gesandten

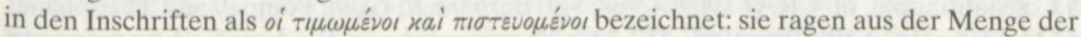
Bürger durch die Ehrbezeugungen und ihre Rolle als Vertrauensleute der Könige und römischen Magistrate hervor. Näheres bei: Ivana Savalli-Lestrade, Des ,Amis‘ des rois aux ,Amis‘ des Romains. Amitié et engagement politique dans les cités grecques à l'époque hellénistique, in: $\mathrm{RPh} 72,1998,65-86$.

16 Die dauerhaft an die verschiedenen hellenistischen Höfe (im phrygischen Kelainai, in Alexandreia, Pella, Babylon, Seleukeia am Tigris, Demetrias in Magnesia oder in den nordsyrischen Städten Antiocheia, Seleukeia, Ladoikeia und Apameia) gebundenen Funktionseliten werden im vorliegenden Beitrag nicht erörtert. S. hierzu immer noch grundlegend: Christian Habicht, Die herrschende Gesellschaft in den hellenistischen Monarchien, in: VSWG 45, 1958, 1-16; Eckart Olshausen, Prosopographie der hellenistischen Königsgesandten I. Löwen 1974; Rolf Strootman, De vrienden van de vorst: het koniklijk hof in de Hellenistische rijken, in: Lampas 38, 2005, 184-197; Gabriel Herman, The ,Friends' of the Early Hellenistic Rulers. Servants or Officials?, in: Talanta 12/13, 1980/81, 103-149; speziell zu einzelnen Monarchien: Sylvie Le Bohec, Les philoi des rois Antigonides, in: REG 98, 1985, 93-124; dies., L'entourage royal à la cour des Antigonides, in: Edmond Lévy (Ed.), Le système palatial en Orient, en Grèce et à Rome. Straßburg 1987, 315-326; Leon Mooren, The Aulic Titulature in Ptolemaic Egypt. Introduction and Prosopography. Brüssel 1975; ders., La hiérarchie de cour Ptolémaique. Contribution à l'étude des institutions et des classes dirigeantes à l'époque hellénistique. Löwen 1977; Gregor Weber, Dichtung und höfische Gesellschaft. Die Rezeption von Zeitgeschichte am Hof der ersten drei Ptolemäer. Stuttgart 1993; Franca Landucci Gattinoni, Lisimaco di Tracia. Un sovrano nella prospettiva del primo ellenismo. Mailand 1992; Carlo Franco, Il regno di Lisimaco. Strutture amministrative e rapporti con le città. Pisa 1993, 192-201. $17 \mathrm{Zu}$ Kallias von Sphettos (Athen 270/69 v. Chr.) s. Thomas L. Shear, Kallias of Sphettos and the Revolt of Athens in 286 B.C. Princeton 1978; Christian Habicht, Athen. Die Geschichte der Stadt in hellenistischer Zeit. München 1995, 102f., $132 \mathrm{f}$. 
Eirenias von Milet bei Eumenes ${ }^{18}$, Menippos und Polemaios und ihre erfolgreichen Verhandlungen mit römischen Statthaltern und dem Senat, schließlich Theophanes von Mytilene und sein enges Verhältnis zu Pompeius, Theopompos von Knidos zu Caesar. ${ }^{19}$

Solche Vermittlerdienste leisteten die Honoratioren, wie man betonen muß, im Regelfall als Träger hoher städtischer Ämter und Priestertümer. ${ }^{20}$ Daß sie gelegentlich auch ohne Amt bei den Königen und später bei den römischen Magistraten intervenierten, versteht sich von selbst; allerdings wurde infolgedessen die Distanz zum Demos unweigerlich größer - zunächst im räumlichen Sinne, da sich diese Honoratioren, wenn sie sich für ihre Heimat verwendeten, nicht in der Stadt befanden, sondern am Hof und im Gefolge des Königs (z. B. Gorgos und Minnion von Iasos bei Alexander; Theophanes von Mytilene bei Pompeius) ${ }^{21}$, gewiß aber vergrößerte sich der Abstand zwi-

18 Peter Herrmann, Neue Urkunden zur Geschichte Milets im 2.Jhd. v. Chr., in: MDAI (I) $15,1965,71-117=$ SEG 36, 1046 (Milet 167/66-159 v. Chr.) = OGIS $763=$ Milet I 9 Nr. $306=$ HGI III 480 .

$19 \mathrm{Zu}$ Polemaios, der für sein vielfältiges politisches Engagement von der Bürgerschaft reich geehrt wird, s. Jeanne Robert/Louis Robert, Claros I. Décrets héllénistique. Paris 1989; Gustav A. Lehmann, Römischer Tod in Kolophon/Klaros. Neue Quellen zum Status der ,freien' Polisstaaten an der Westküste Kleinasiens im späten zweiten Jahrhundert v. Chr. Göttingen 1998; Theophanes von Mytilene: Louis Robert, Théophane de Mytilène à Constantinople, in: CRAI 1969, 42-64; vgl. Barbara K. Gold, Pompey and Theophanes of Mytilene, in: AJPh 106, 1985, 312-327; Theopompos von Knidos, der zusammen mit seinem Sohn Artemidoros am Abschluß des Bündnisvertrages der Knidier mit Rom beteiligt war: Gustav Hirschfeld, C. Iulius Theupompus of Cnidus, in: JHS 7, 1886, 286-290; IvKnidos $43 \mathrm{f}$.

$20 \mathrm{~S}$. die beiden Standardwerke zur Führungsschicht in den griechischen Städten: Philippe Gauthier, Les cités grecques et leurs bienfaiteurs (IVe-Irer siècle av. J.C.), Contribution à l'histoire des institutions. Paris 1985; Friedemann Quaß, Die Honoratiorenschicht in den Städten des griechischen Ostens. Stuttgart 1993; vgl. auch Ivana Savalli Lestrade, Remarques sur les élites dans les poleis hellénistiques, in: Mireille Cébeillac-Gervasoni/ Laurent Lamoine (Eds.), Les élites et leurs facettes. Les élites locales dans le monde hellénistique et romain. Rom/Clermont Ferrand 2003, 51-64; Vivi Andreou, Remarques sur l'histoire des classes dirigeantes de Milet, in: Leon Mooren (Ed.), Politics, Administration and Society in the Hellenistic and Roman World. Löwen 2000, 1-13. Zur Herrschaftsstruktur innerhalb der hellenistischen Städten und zur Übertragbarkeit der Weberianischen Kategorie der ,Honoratiorenherrschaft' (bei formal fortbestehender Demokratie): Friedemann Quaß, Bemerkungen zur ,Honoratiorenherrschaft' in den griechischen Städten der hellenistischen Zeit, in: Gymnasium 99, 1992, 422-434. Speziell zur städtischen Führungsschicht in der römischen Welt: Mireille Cébeillac-Gervasoni (Ed.), Autocélébration des élites locales dans le monde romain: contextes, images, textes $\left(\mathrm{IJ}^{\mathrm{e}} \mathrm{s} . \mathrm{av}\right.$. J.-C.-III ${ }^{\mathrm{e}}$ s.ap. J.-C.). Clermont-Ferrand 2004; dies. (Ed.), Les élites municipales de l'Italie péninsulaire de la mort de César à la mort de Domitien entre continuité et rupture: classes sociales dirigeantes et pouvoir central. Rom 2000; dies., Les magistrats des cités italiennes de la seconde Guerre Punique à Auguste: le Latium et la Campanie. Rom 1998.

${ }^{21} \mathrm{Zu}$ Gorgos, Hoplophylax bei Alexander, und Minnion, die sich für die vertriebenen Samier und für ihre Heimatstadt verwendeten (Syll. ${ }^{3}$ 307. 312), s. Helmut Berve, Das 
schen Honoratioren und Demos auch in ideeller Hinsicht, gerade weil erstere durch die Gunstbeweise verschiedener Könige weitaus stärker zum Objekt öffentlicher Wertschätzung wurden.

Trotz alledem: Es hat den Anschein, als ob das Verhältnis zwischen der städtischen Führungsschicht und der Masse der einfachen Bürger im großen und ganzen seit der klassischen Zeit keine grundlegende Änderung erfuhr. Es spricht nichts für die Annahme, daß vom 5. bis zum 1. Jahrhundert v. Chr. der Anteil politisch aktiver Bürger zurückgegangen wäre und die Verbundenheit des einzelnen Bürgers mit der eigenen Polis an Intensität verloren hätte. ${ }^{22}$ Die meisten Bürger genügten nach wie vor ihren Pflichten, wenn sie bei der Verteidigung der Stadt ihren Militärdienst ableisteten, die Volksversammlung besuchten und an den Abstimmungen teilnahmen, ein Jahr lang dem Rat angehörten, gelegentlich als Schöffen zu Gericht saßen und möglicherweise das eine oder andere Amt versahen.

Immer war es jedoch eine Minderheit, ein kleiner Kreis der städtischen Elite, aus dem sich die Strategen, die Reiterführer und Trierarchen, die Redner und Meinungsführer in den öffentlichen Versammlungen, die Finanzbeamten und die Gesandten rekrutierten. In Athen etwa hatte Perikles bekanntlich viele Jahre lang den Kurs der Politik bestimmt (Thuk. 2,65,9), und

Alexanderreich auf prosopographischer Grundlage. Bd.2. München 1926, Nr. 236. Zu Theophanes: Richard Laqueur, Art. „Theophanes (Nr.1)“, in: RE 5A, 1934, 2090-2127; Barbara K. Gold, Pompey and Theophanes of Mytilene, in: AJPh 106, 1985, 312-327 (mit weiterer Literatur). Er war bereits vor seinem Kontakt zu Pompeius Prytane und damit eine hochrangige Persönlichkeit im öffentlichen Lebens seiner Heimatstadt: Vasilis $A$. Anastasiadis/George A. Souris, Theophanes of Mytilene: A New Inscription Relating to His Early Career, in: Chiron 22, 1992, 377-383.

22 Gegen die Ansicht, daß die hellenistischen Städte nur noch dem Namen nach eine demokratische Verfassung besaßen, faktisch jedoch zumeist von einzelnen Honoratioren beherrscht wurden (so nachdrücklich insbesondere: Paul Veyne, Le pain et le cirque. Paris 1976, 201-209), s. die Erwiderungen von Lehmann, Römischer Tod (wie Anm. 19), 28-32; Erich Gruen, The Polis in the Hellenistic World, in: Ralph M. Rosen/Joseph Farrell (Eds.), Nomodeiktes. Greek Studies in Honor of Martin Ostwald. Ann Arbor 1993, 339-354; Paul Gauthier, Quorum et participation civique dans les démocraties grecques, in: Claude Nicolet (Ed.), Du pouvoir dans l'antiquité: mots et realités. Genf 1990, 73-99; ders., Les cités hellenistiques: Epigraphie et histoire des institutions et des regimes politiques, in: Chrysis Pélékidis (Ed.), Actes du $6^{\mathrm{e}}$ Congrès internationale d'épigraphie grecque et latine, Athênes 1982. Athen 1984, 82-107, bes. 96-97. Aus einer anderen Perspektive: Hartmut Leppin, Theophrasts ,Charaktere und die Bürgermentalität in Athen im Übergang zum Hellenismus, in: Klio 84, 2002, 37-56. Vgl. die in jüngerer Zeit entbrannte Diskussion um die historische Bewertung der, demokratisch'verfaßten Städte: Volker Grieb, Hellenistische Demokratie. Politische Organisation und Struktur in freien griechischen Poleis nach Alexander dem Großen. Stuttgart 2007; Susanne Carlsson, Hellenistic Democracies. Freedom, Independence and Political Procedure im some East Greek City-States. Uppsala 2005; Sviatoslav Dmitriev, City Government in Hellenistic and Roman Asia Minor. Oxford 2005; Pierre Fröhlich, Les cités grecques et le contrôle des magistrates (IVe-Ier siècle av. J.C.). Genf 2004. 
auch im ersten vorchristlichen Jahrhundert verhielt es sich in anderen griechischen Städten noch ähnlich: Einige wenige Männer waren oftmals für lange Zeit die Führer ihrer Poleis, in Nysa (und später dann auch in Tralleis) waren es beispielsweise der reiche Chairemon und sein Sohn Pythodoros ${ }^{23}$, in Mylasa die Redner Euthydemos und sein lokaler Rivale Hybreas, in Laodikeia am Lykos der Rhetor Zenon und sein Sohn Polemon ${ }^{24}$, in Athen Chremonides und Glaukon ${ }^{25}$ um nur einige zu nennen, und dort bereits am Ausgang des 4. Jahrhunderts v. Chr. (zusammen mit anderen) den Eteobutaden Lykurg, den ich an den Anfang dieser Reihe, demokratisch gesinnter Oligarchen'stellen möchte. ${ }^{26}$

Worin sich die städtischen Führungsschichten aus der Menge der gewöhnlichen Bürger heraushoben, waren nach Aristoteles (pol. 1291b 14-30) in der

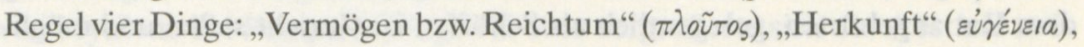
„körperliche und geistige Bildung“ (

23 Im Krieg gegen Mithradates hielt die Familie Rom bedingungslos die Treue (Strab. 14,1,42 p. 649). Pythodoros tritt später als Asiarch in Erscheinung: Rudolf Hanslik, Art. „Pythodoros (Nr. 13)“, in: RE 24/1, 1963, 590-592.

24 Euthydemos und Hybreas, die von Strabon als „Redner und zugleich Demagogen der Stadt" bezeichnet werden und entsprechend die Debatten um die Ausrichtung der Politik bestimmten (Strab. 13,4,5 p. 630; 14,2,24 p. 659f.; Val. Max. 9,14): Franz Susemihl, Geschichte der griechischen Literatur in Alexandrinischer Zeit. Bd.2. Leipzig 1892, 499f. Zu Zenon und Polemon, den nach Aussage Strabons ,Wohltätern' Laodikeias: Strab. $12,8,16$ p. 578 . Polemon wurde römischer Klientelfürst und seit dem Jahr 14 v. Chr. auch König des Bosporianischen Reiches: Wolfgang Hoben, Untersuchung zur Stellung kleinasiatischer Dynasten. Diss. Mainz 1969, 39-53 .

25 Erst kurz vor dem Ausbruch des Chremonideischen Krieges 267 v. Chr. gewannen diese beiden athenischen Patrioten als oi òn beiträge, die Athen. 6,250-251 referiert (aus den Hypomnemata des Hegesandros); vgl. William S. Ferguson, Hellenistic Athens. London 1911, 176-185; Habicht, Athen (wie Anm.17), 147-153. Speziell zur angeführten Stelle: Heinz Heinen, Untersuchungen zur hellenistischen Geschichte des 3. Jhs. v. Chr. - Zur Geschichte der Zeit des Ptolemaios Keraunos und zum Chremonideischen Krieg. Wiesbaden 1972, 206f. mit Anm. 456.

26 Ausführlich zu seiner Person: Sally Humphreys, Lycurgus of Butadae. An Athenian Aristocrat, in: John W. Eadie/Josiah Ober (Eds.), The Craft of the Ancient Historian. Essays in Honor of Chester G. Starr. Lanham 1985, 199-252. Zu seinem Priesteramt und zur Anklage des Leokrates: Jon D. Mikalson, Religion in Hellenistic Athens. Berkeley 1998, 11-45.

27 Vincent Gabrielsen, The Naval Aristocracy of Hellenistic Rhodes. Aarhus 1997, 15f., weist zu Recht darauf hin, daß nicht jeder politisch Ambitionierte über alle diese vier Merkmale gleichermaßen verfügen mußte. Vor allem dem persönlichen aus Grundbesitz und Handel gewonnenen Vermögen und der Demonstration und des Einsatzes desselben in Euergesien und Epidoseis kam seit dem 3. Jh. v. Chr. eine immer größere Bedeutung zu, zumal innere Krisen wie etwa Getreideengpässe sowie äußere Kriege die Not der Städte und deren Abhängigkeit von ihren wenigen Gönnern nur noch vergrößerte. $\mathrm{Zu}$ den sozialen und ökonomischen Voraussetzungen s. den Überblick: John K. Davies, Cultural, Social and Economic Features of the Hellenistic World, in: $\mathrm{CAH}^{2} 7 / 1,257-320$. Vgl. hiermit die Lage der Notabeln im klassischen Athen: ders., Athenian Propertied Families. Oxford 1971; ders., Wealth and the Power of Wealth in Classical Athens. New York 1986. 
sind jedoch nur äußere Merkmale, die jeder Bürger als bloß private Person beanspruchen konnte. Von weitaus größerer Bedeutung war es, Ämter zu übernehmen und dadurch anerkanntermaßen öffentlich herauszuragen. ${ }^{28}$ Sinnfällig wurde dies bei den städtischen Festen. In deren Verlauf trat die Prominenz einiger Bürger und ihrer Familien für alle Teilnehmer sichtbar hervor: wenn diese herausragenden Männer bei den musischen, gymnischen und hippischen Agonen im Theater, Stadion oder Hippodrom die Ehrenplätze der Prohedrie einnahmen ${ }^{29}$ oder wenn sie in ihrer Funktion als Magistrate oder Priester (oder sogar als Stifter von Festen) oder ihre Söhne als Sieger von Agonen die Prozessionen im Rahmen städtischer Feste anführten und hierbei das Privileg genossen, exklusiv unter den ansonsten ausschließlich weißgewandeten Festzugsteilnehmern goldverzierte oder purpurne Gewänder zu tragen. ${ }^{30}$

Doch nicht nur aufgrund ihres Reichtums, ihrer Herkunft und ihrer sozialen Autorität führten die letzteren die Polis an, sondern auch aufgrund ihrer umfassenden körperlichen und intellektuellen Ausbildung, die sie in privatem Unterricht und in den Gymnasien empfangen hatten. Durch diese paideia verfügten sie über rhetorische Techniken, ethisches Wissen, literarische und andere Fachkenntnisse, die sie in die Lage versetzten, die öffentlichen Debatten im Rat und der Volksversammlung zu bestimmen und vor Gericht als Ankläger oder Verteidiger aufzutreten. ${ }^{31}$ Sofern die städtischen chen entsprach auch der allgemeinen Wahrnehmung seitens der Masse der gewöhnti$106,1976,29-59$.

${ }^{29} \mathrm{Zu}$ dieser in Athen seit dem 4.Jh. v. Chr. auftretenden Form der Ehrung: Alan S. Henry, Honours and Privileges in Athenian Decrees. The Principal Formulae of Athenian Honorary Decrees. Hildesheim/Zürich/New York 1983, 291-294; vgl. Christian Marek, Die Proxenie. Frankfurt am Main/Bern 1984, 150, 156. Am besten ist das Phänomen von der epigraphischen und archäologischen Seite her am Dionysostheater zu studieren: Michael Maass, Die Prohedrie des Dionysostheaters in Athen. München 1972.

${ }^{30} \mathrm{Zu}$ den städtischen Festen allgemein: Angelos Chaniotis, Sich selbst feiern? Städtische Feste des Hellenismus im Spannungsfeld von Religion und Politik, in: Michael Wörrle/ Paul Zanker (Hrsg.), Stadtbild und Bürgerbild im Hellenismus. München 1995, 147-192. Die führenden städtischen Beamten und Priester standen an der Spitze solcher Umzüge: Jens Köhler, Pompai. Untersuchungen zur hellenistischen Festkultur. Frankfurt am Main u. a. 1996, bes. 46-53. 186 (= Taf. 6: Übersicht zur Pompé am 12. Artemision im Rahmen des Festes für Zeus Sosipolis in Magnesia [Syll. ${ }^{3}$ 589, Z. 32-59] und für Artemis Leukophryene [Syll. ${ }^{3}$ 695]). 54-60. 189 (= Taf. 9: Prozession für Diodoros Pasparos in Pergamon: MDAI(A) 32, 1907, 243ff. Nr.4 = IGR IV 292), 163-165 (generell zum Auftreten der Führungsschicht). Zum Privileg, sich besonders kostbar zu kleiden: Demosth. 21,22 (als Chorege in einem Goldgewand); vgl. Diod. 4,83,7 (Chrysophorie und Purpurtracht als Privilegien beim Aphroditefest in Eryx); vgl. Louis Robert, Un décret de Pergame, in: BCH 108, 1984, 484-486 (= ders., Documents d'Asie Mineure. Paris 1985, 472-474).

${ }^{31}$ Näheres hierzu bei: Peter Scholz, Zur Bedeutung von Rede und Rhetorik in der hellenistischen Paideia und Politik, in: Christoph Neumeister/Wulf Raeck (Hrsg.) Rede und Redner. Bewertung und Darstellung in den antiken Kulturen. Möhnesee 2000, 95-118. 
Eliten ,sich entschlossen hatten, zugunsten der Demokratie und der Freiheit auf anständige Art und Weise politisch tätig zu sein“, wie es im erst 307/06 v. Chr. postum von den Athenern verliehenen Ehrendekret für Lykurg heißt ${ }^{32}$, fühlten sie sich besonders stark dazu verpflichtet, den Normen der Bürgergemeinde zu Geltung und Wirksamkeit zu verhelfen: durch das Wort, indem sie in den Versammlungen Ratschläge erteilten und die Bürger über angemessenes Verhalten belehrten, und durch die Tat, indem sie entweder kostspielige Ämter oder schwierige politische Missionen übernahmen.

Die maßgebliche, gegenüber der klassischen Zeit qualitativ grundlegende Neuerung im Verhältnis zwischen Demos und städtischer Elite bestand zweifellos darin, daß seit dem Beginn des 3. Jahrhundert v. Chr. erstmals einzelne Bürger demonstrativ in ehrenden Beschlüssen herausgehoben wurden. ${ }^{33}$ Erstmals fanden - in offiziellen Dokumenten und auf breiter Basis - die Führungsqualitäten und Vorrangstellung dieser Klasse der Honoratioren, Oligarchen oder Notabeln Anerkennung. Allerdings kam darin auch die wachsende soziale Kluft zwischen Demos und Führungsschicht gewissermaßen offiziell zum Ausdruck. Gemessen an den Mitteln, die der athenische Demos im 5. und 4. Jahrhundert v. Chr. zur Disziplinierung der führenden Politiker einsetzte, fehlte den Kontrollen der Notabeln durch die Bürgerschaften in den meisten Städten jede Schärfe. Auch wenn die politische Gleichheit im klassischen Athen nur die Gleichheit vor dem Gesetz und die gleichen Möglichkeiten, Rechte und Pflichten bei der politischen Teilhabe bedeutete, so war der athenische Demos sehr darum bemüht, daß keiner der namhaften Politiker sich wirklich dauerhaft seiner politischen Führungsstellung sicher fühlen durfte. Dies gelang den Athenern bekanntlich zunächst durch das Mittel des Ostrakismos, dann verstärkt durch die Popularklage und durch das Volksgericht beziehungsweise durch die Volksversammlung. Selbst wenn jemand über Jahre hinweg eine so herausragende Führungsrolle wie Perikles eingenommen hatte, gestand ihm die Bürgerschaft zu Lebzeiten nur kleinere Anerkennungen zu, aus denen kaum die herausgehobene Stellung des betreffenden Mannes abzulesen war.

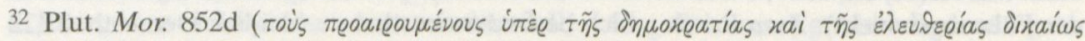

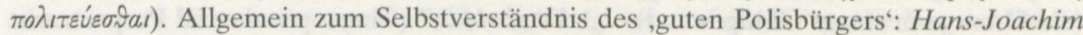
Gehrke, Bürgerliches Selbstverständnis und Polisidentität im Hellenismus, in: KarlJoachim Hölkeskamp/Jörn Rüsen/Elke Stein-Hölkeskamp (Hrsg.), Sinn (in) der Antike. Orientierungssysteme, Leitbilder und Wertkonzepte im Altertum. Mainz 2003, 225-254.

33 S. hierzu grundlegend: Klaus Rosen, Ehrendekrete, Biographie und Geschichtsschreibung. Zum Wandel der Polis im frühen Hellenismus, in: Chiron 17, 1987, $277-292$. 


\section{Die Exklusivierung und Aristokratisierung der Führungsschicht im 2. und 1. Jahrhundert v. Chr.}

Die wachsende Exklusivierung der städtischen Oberschicht läßt sich deutlich an den Inhalten, an der Sprache und Form der späthellenistischen Ehrendekrete ablesen, wie insbesondere Christian Habicht hervorgehoben hat. ${ }^{34}$ Seit dem 2. Jahrhundert v. Chr. werden die Ehren vervielfältigt. Dies bedeutete: Statt einer Statue wurden mehrere an verschiedenen Stellen der Stadt aufgestellt und Kranzverleihungen in periodischen Abständen wiederholt. ${ }^{35}$ Die bis dahin üblichen höchsten Ehren, Statuenverleihung, Speisung am Staatsherd und Prohedrie an den Festen, wurden häufiger und im Vergleich zum 4.Jahrhundert aufgrund geringfügigerer Verdienste verliehen; ja manche Bürger, wie beispielsweise Diodoros Pasparos in Pergamon ${ }^{36}$ und C. Iulius Artemidorus in Knidos, der Sohn des bereits erwähnten Theopompos, wurden bei außergewöhnlichen Verdiensten sogar mit kultischen Ehren bedacht - und das bereits zu Lebzeiten. Sie beide sind gut dokumentierte Beispiele für den Typus des herausragenden städtischen Euergeten im späten Hellenismus, der im lokalen Rahmen eine nahezu monarchische Stellung einnahm.

Ein völlig neues Phänomen ist im 1. Jahrhundert v. Chr. schließlich, daß in den Ehrendekreten aus dieser Zeit von der Bürgerschaft weitere Ehren nach dem Tod eines herausragenden Mannes angekündigt werden. Die Tendenz, rascher und umstandsloser als in klassischer Zeit private Heroenkulte zu genehmigen oder sogar öffentliche Kulte für einen Euergeten einzurichten ${ }^{37}$, fand hierin ihren konsequenten Höhepunkt: Der Tod bildete für die Bürgerschaft den Anlaß, den Verstorbenen erneut mit einem Kranz zu ehren: der Leichnam, nicht die Statue wurde dabei bekränzt - postum gewissermaßen

34 Christian Habicht, Ist ein ,Honoratiorenregime` das Kennzeichen der Stadt im späteren Hellenismus?, in: Wörrle/Zanker (Hrsg.), Stadtbild (wie Anm. 30), 87-92.

35 Wulf Raeck, Der mehrfache Apollodoros. Zur Präsenz des Bürgers im hellenistischen Stadtbild am Beispiel von Priene, in: Wörrle/Zanker (Hrsg.), Stadtbild (wie Anm.30), 231-239; Paul Zanker, Brüche im Bürgerbild? Zur bürgerlichen Selbstdarstellung in den hellenistischen Städten, in: ebd. 251-273.

${ }^{36}$ Diodoros bekleidete in Pergamon höchste städtische (Gymnasiarchie) und religiöse Ämter (Archiereus und Priester des Zeus Megistos) und trat zugleich als großzügiger Euerget (Kult- und Baustiftungen) auf (z. B. IvPergamon 256; IGR IV 292-294): Christopher Jones, Diodoros Pasparos and the Nikephoria of Pergamon, in: Chiron 4, 1974, 183-205; ders., Diodoros Pasparos Revisited, in: Chiron 30, 2000, 1-14.

37 Zum archäologischen Befund: Ingeborg Kader, Heroa und Memorialbauten, in: Wörrle/Zanker (Hrsg.), Stadtbild (wie Anm.30), 199-229. Ein Beispiel illustriert die neuartige öffentliche Sichtbarkeit der Ehren für herausgehobene Einzelne bzw. deren Familien: So wurden in Messene sechs Männer und vier Frauen, Mitglieder der Familie des olympischen Siegers Antisthenes, Sohn des Polystratos, in einem Gemeinschaftsgrabbau bestattet, der sich unmittelbar gegenüber dem Ratsgebäude befand. Zur Identifikation: Christian Habicht, Zwei Familien aus Messene, in: ZPE 115, 1997, 125-127. 
für sein politisches Lebenswerk ausgezeichnet. Darüber hinaus gewährte die Bürgerschaft häufig öffentliches Geleit zum Grab durch die Epheben, die „jungen Männer" ( (véı) und die städtischen Magistrate, und schließlich eine feierliche Beisetzung auf Staatskosten - hierbei gelegentlich sogar innerhalb der Mauern der Stadt, also auf der Agora oder in einem Gymnasion. ${ }^{38}$

Daher wird man wohl sagen dürfen: Mit der Bestattung besonders herausragender Männer im Zentrum einer Stadt hatte der Weg der Reichen und Vornehmen in die Polis gewissermaßen ihren Abschluß gefunden - sie waren zu anerkannten und geschätzten Führern des Volkes geworden. Deutlichster Hinweis darauf ist zum einen der Umstand, daß im späten Hellenismus sogar Frauen wie Archippe in Kyme oder Epie in Thasos als Repräsentanten ihrer Familie auftraten und ihren Heimatstädten reiche Zuwendungen zukommen ließen ${ }^{39}$, zum anderen, daß in der Terminologie der Ehrendekrete nun auch erstmals von den „Ersten“ (oi $\pi \varrho \tilde{\omega} \tau o ı / \pi \varrho \omega \tau \varepsilon \dot{v} о \nu \tau \varepsilon \zeta)$ in der Stadt ${ }^{40}$ die Rede ist, mithin seit 100 v. Chr. erstmals die Führungsstellung ausdrücklich benannt und damit auch erstmals in den Dekreten eine soziale Gliederung der Bürgerschaft aufscheint. Die demokratischen Institutionen wurden zwar nicht obsolet, jedoch veränderte sich deren Funktion: dort erhielten die ,wenigen“ Meinungsführer die für ihre politische Betätigung erforderliche Zustimmung und ihren Auftrag - und zwar nicht im Kollektiv, sondern als eigenständig und auf eigene Kosten agierende Politiker.

Selbst wenn die Abhängigkeit der Bürgerschaften von den politischen Verbindungen der Honoratioren in den Beschlüssen überzeichnet dargestellt sein mag: nicht nur diese, sondern auch die wirtschaftliche Abhängigkeit von den „Wenigen“ muß in jedem Fall stark gewesen sein: Die Bezahlung der mit

$38 \mathrm{Zu}$ diesem Phänomen s. jetzt umfassend: Edouard Chiricat, Funérailles publiques et enterrement au gymnase à l' époque hellénistique, in: Pierre Fröhlich/Christel Müller (Eds.), Citoyenneté et Participation à la Basse Époque Hellénistique. Actes de la table ronde des 22 et 23 mai 2004. Paris/Genf 2005, 225-256.

39 Speziell zu Archippe s. das Konvolut an Beschlüssen zu ihren Ehren auf einem Pfeilermonument aus Kyme (nach 130 v. Chr.): SEG 33, 1035-1041 = IvKyme 13, S. 27-42 und Hasan Malay, Three Decrees from Kyme, in: EA 2, 1983, 1-20; Ivana Savalli-Lestrade, Archippè de Kymè, la bienfaitrice, in: Nicole Loraux (Ed.), La Grèce au féminin. Paris 2003, 247-295. Zu Epie von Thasos: Francois Salviat, Décrets pour Épiè fille de Dionysos: déesses et sanctuaires thasiens, in: BCH 83, 1959, 326-397. Weitere prominente Beispiele sind etwa Megaklea von Mytilene (IG XII 2,461: 2. Jh. v. Chr.) oder Theodosia von Arkesine auf Amorgos (IG XII 7,49: 1.Jh. v. Chr.). Allgemein zu diesen ,Wohltäterinnen': Riet van Bremen, The Limits of Participation. Women and Civic Life in the Greek East in the Hellenistic and Roman Periods. Amsterdam 1996, bes. 13-19 (Archippe); vgl. neuerdings auch Regula Frei-StolbalAnne Bielman (Eds.), Femmes et vie publique dans l'Antiquité gréco-romaine. Lausanne 1998; Anne Bielman, Femmes en public dans le monde hellénistique, Paris 2002.

40 Z.B. im Dekret für Serapion, Sohn des Dionysios, aus Aigiale wird die Verwandt-

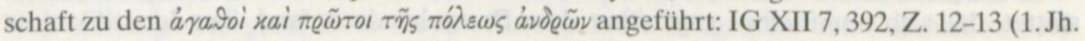
v. Chr.). 
den Ämtern und weiten Gesandtschaftsreisen verbundenen Kosten aus eigenem Vermögen, die Finanzierung des öffentlichen Lebens von der Getreideversorgung, des Betriebs der Gymnasien, der städtischen Feste und Bauten bis hin zur Gewährung von Schuldenerlassen, Krediten und Bürgschaften all das verstärkte in jedem Fall die in den politischen Begriffen bereits festgestellte Tendenz der schleichenden Exklusivierung der politischen Führungsschicht. Im Extremfall wurde der Bürgerverband dem Oikos, dem Haushalt eines Honoratioren, zugerechnet: So wird beispielsweise der Ephebarch und Honoratiorensohn Melanion in Iasos dafür gelobt, daß er „sich liebevoll, aber auch in einer Weise gegenüber den Eltern und den Verwandten benommen habe, wie es sich für einen besonnenen und gebildeten jungen Mann gehöre, und sich gegenüber allen Bürgern wohlwollend und generell so verhalten habe, daß es ihm zur Ehre gereichte" ". ${ }^{41}$ Sein häusliches Betragen wird hier somit zum Maßstab seines öffentlichen Auftretens. Schon seine Jovialität wird als Beweis politischer Tugend gewertet. Überhaupt wurden die Bürgerschaften im 1.Jahrhundert v. Chr. zunehmend zu Gästen der Euergeten. Öffentliche Bankette und Empfänge aus Anlaß von Amtsantritten wurden nun häufig in den Privathäusern der Honoratioren abgehalten; oder die gesamte Bürgerschaft durfte sich zur Hochzeitsgesellschaft zählen. ${ }^{42}$ Einladungen dieser Art wurden bisweilen mit so großer Sympathie ( $\sigma \tau \circ \varrho \gamma \eta$ ) erwidert, daß manche Bürgerschaft sich nicht scheute, sogar öffentliche Gebete und Opfer zugunsten eines erkrankten Honoratioren anzuordnen.

Darin fügt sich gut die Beobachtung ein, daß die in der zweiten Hälfte des 2.Jahrhunderts immer häufiger werdenden Dekrete zu Ehren verdienter Männer die Rolle der Bürgerschaft als ein weitgehend passives Kollektiv beschreiben: Der Demos empfängt von diesen übermächtigen Männern „Wohl-

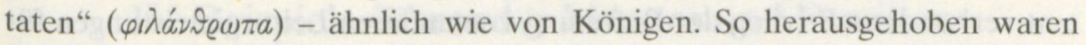
diese Euergeten im 1.Jahrhundert v. Chr., daß es etwa in einem Dekret aus Priene heißt, Moschion habe der Stadt Getreide zukommen lassen, weil er wollte, daß die Bürger sich in allem in einem Zustand materieller Sorglosigkeit (sủòauovía) befänden. ${ }^{43}$

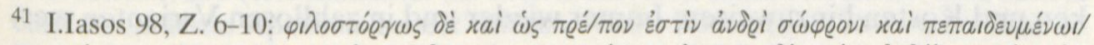

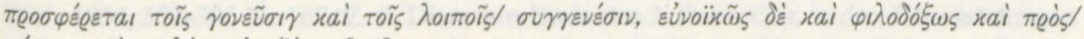

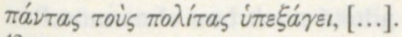

${ }^{42}$ S. hierzu neuerdings umfassend: Elena Mango, Bankette im hellenistischen Gymnasion, in: Daniel Kah/Peter Scholz (Hrsg.), Das hellenistische Gymnasion. Berlin 2004, 273-312.

43 IvPriene 108, Z. 99-100. Umfassend zu diesem Phänomen: Philippe Gauthier, Les cités grecques et leur bienfaiteurs (IVe- $\mathrm{I}^{\mathrm{er}}$ siècle av. J.-C.). Contribution à l'histoire des institutions. Athen 1985; Quaß, Honoratiorenschicht (wie Anm. 20); Paul Veyne, Le pain et le cirque. Sociologie historique d'un pluralisme politique. Paris 1976 [dt. Ausgabe: Brot und Spiele. Gesellschaftliche Macht und politische Herrschaft in der Antike. Frankfurt am Main 1988]. 
Gerade kleinere Poleis waren darauf angewiesen, daß mit vielen Pflichten und hohen Kosten verbundene Ämter besetzt wurden; um so dankbarer waren sie, wenn sich reiche Bürger - häufig jedoch erst nach ausdrücklicher Aufforderung der Gemeinde - bereit fanden, ein solches zu bekleiden. Trotz aller Anstrengungen seitens der Bürgerschaften blieben gleichwohl manche Priester- und andere Ämter offenkundig unbesetzt, weil sie, wie ein Dekret in eindrucksvoller Offenheit eingestand, „nichts einbrachten und hohe Aufwendungen mit sich brachten"; und auch für manche eponyme Ämter war es häufig schwierig, Kandidaten zu finden, da, wie eine andere Inschrift nicht weniger freimütig verrät, ,niemand sich dazu hergab“44.

Die Stilisierung engagierter reicher Bürger zu Musterbürgern und ihre übertriebene Glorifizierung weist also gerade auf ein allenthalben anzutreffendes Desinteresse der reichen Bürger an der Übernahme öffentlicher Pflichten. ${ }^{45}$ Ganz unverhohlen entzogen sich manche den ihnen angetragenen Wünschen der Bürgerschaften. Da letztere gerade in den kleinen Städten über keinerlei Sanktions- und Kontrollmöglichkeiten verfügten, um die wenigen Reichen und Mächtigen an sich zu binden und bei Laune zu halten, blieb ihnen zumeist nur der Weg der Steigerung der Ehren in jeder erdenklichen Weise.

Oft scheint der Einsatz vieler reicher Bürger bei der Ausübung dieser Ämter zumindest halbherzig gewesen zu sein. Es lohnt sich, zu diesem Zweck die Dekrete unter umgekehrten Vorzeichen zu lesen, da dann die Schattenseiten der Ämterübernahme um so deutlicher hervortreten: Warum etwa wurde Moschion von Priene besonders dafür gerühmt, daß er sich mit voller Verantwortlichkeit den öffentlichen Angelegenheiten zugewandt habe ${ }^{46}$, warum wurde Polemaios von Kolophon dafür gelobt, daß er das mit dem Priesteramt verbundene Privileg der Befreiung von anderen Leiturgieleistungen für die Polis nicht in Anspruch genommen hatte? ${ }^{47}$ Diese Beispiele legen nahe, daß sich ganz offenkundig nicht alle Honoratioren damit anfreunden konnten, stets im Sinne des Gemeinwohls zu denken und zu handeln. ${ }^{48}$ Nicht alle stellten sich vorbehaltlos und bereitwillig zur Verfügung. ${ }^{49}$ Gerade deshalb wurde es notwendig, in den Ehrendekreten nachdrücklich auf die mit dem politischen Engagement der Honoratioren verbundenen Belastungen, Risiken und Kosten hinzuweisen: Immer wieder und in zahllosen Varianten wer-

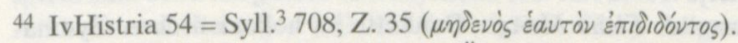

45 So ein Ergebnis eines virtuosen Überblicks über das in den hellenistischen Ehrendekreten hervortretende Bürgerbild: Michael Wörrle, Vom tugendsamen Jüngling zum ,gestreßten' Euergeten. Überlegungen zum Bürgerbild hellenistischer Ehrendekrete, in: Wörrle/Zanker (Hrsg.), Stadtbild (wie Anm.30), 241-250.

46 IvPriene 108 Z. 213 ff. (129/100 v. Chr.).

47 Polemaios III Z. $13 \mathrm{ff}$.

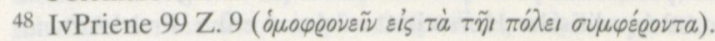

49 IvPriene 108 Z. 313. 
den in pathetischer Übersteigerung die Anstrengungen ( тóvoı), Belastungen (ко́тоı), schmerzvollen Erfahrungen (какота vía), Risiken und Gefahren (xívovvoı) angeführt ${ }^{50}$, oberste Priorität allen Handelns hat der Dienst an der Polis - die führenden Männer werden darin gleichsam zu politischen Masochisten und Übermenschen stilisiert, wie es Michael Wörrle treffend formuliert hat. ${ }^{51}$ Mit der sorgsamen Auflistung ihres gesamten politischen Wirkens wird die selbstquälerische Übernahme all dieser Unannehmlichkeiten letztlich zur politischen Tugend.

Der deutliche Vermerk der Schattenseiten des Euergetenlebens hatte den rhetorischen Effekt, daß die Leistungen der Geehrten in noch hellerem Licht erstrahlten, sie jedoch sich faktisch wie propagandistisch noch weiter von dem Durchschnittsbürger einer Polis, von dessen Alltag, Erfahrungen und Handlungsmöglichkeiten entfernten. Ja, das übertriebene Lob der städtischen Wohltäter muß manchem Bürger schmerzlich die eigene Ohnmacht und Begrenztheit seines Denkens und Handelns vor Augen geführt haben. Denn die Rolle, welche die Ehrendekrete für gewöhnlich dem Demos zuwiesen, war auf das Geschäft des Ehrens beschränkt: Das Volk erkannte den Eifer des Honoratioren an und brachte sie in Form öffentlicher Lobesworte ('́maıvoi), ehrenden Beschlüssen ( $\left.\eta_{\eta} \varphi i_{\sigma} \mu a \tau a\right)$, Statuen- und Kranzverleihungen zum Ausdruck. ${ }^{52}$ Diese Grundkonstellation, das wechselseitige Abhängigkeitsverhältnis zwischen Stifter und Bürgerschaft, wurde gelegentlich auch plastisch in Szene gesetzt: So wurde in Kyme eine Statue der Wohltäterin Archippe zusammen mit einem Kolossalbild des Demos aufgestellt, der dieser einen Kranz aufsetzte. ${ }^{53}$

\section{Beispiele führender Männer und Familien}

Antriebskraft für die außerordentlichen Leistungen einzelner Bürger war das Streben nach individueller Maximierung des öffentlichen Ansehens, des Prestiges, das in der Sprache der Dekrete mit den fast synonym gebrauchten

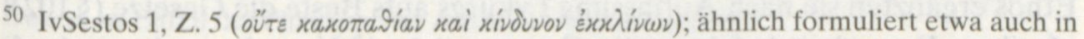
einer Inschrift aus Apollonia bei der Salbake: Jeanne Robert/Louis Robert, La Carie II. Paris 1954, 303-305 Nr. 167, Z. 5. Diese am Ende des 2. Jh.s v. Chr. in den Ehrendekreten aufkommende und dann häufig verwendete Begrifflichkeit (Maurice Holleaux, Études d'épigraphie et d'histoire grecques III: Lagides et Séleucides. Paris 1942, 95) greift zumindest mittelbar die epikureische Sicht auf die Mühsal der politischen Lebensform auf. Zur harschen Kritik Epikurs und der ersten beiden Schülergenerationen am gewöhnlichen Bürgerleben und ihrer theoretischen wie auch praktischen ,Antipolitik's. Peter Scholz, Der Philosoph und die Politik. Stuttgart 1998, 253-314.

51 Wörrle, Vom tugendsamen Jüngling (wie Anm.45), 244.

$52 \mathrm{~S}$. hier beispielsweise nur die Ehrungen, die der Gymnasiarch Menas empfing: IvSestos 1 (= OGIS 339) Z. 39ff. 59ff.

53 SEG 33, 1035 Z 1ff.; 1037, Z. 12 ff.; 1041 Z. 1. 


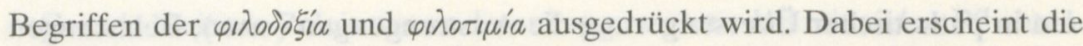
sich im politischen und euergetischen Wirken manifestierende ả@єтฑ́ nicht um ihrer selbst willen erstrebenswert zu sein; sie ist vielmehr nur von Bedeutung, wenn sie bemerkt und möglichst lange Zeit erinnert wird. Diese Funktion erfüllten die Ehrendekrete und die dazugehörigen an exponierten Stellen der Stadt aufgestellten Statuen. Der zwischen 130 und 120 v. Chr. gefaßte Beschluß zu Ehren des Gymnasiarchen Menas aus Sestos ${ }^{54}$ mag hier als besonders eindrückliches Beispiel dienen, um die Bewahrung der öffentlichen Erinnerung an einen städtischen Wohltäter vorzuführen. In der einleitenden Begründung, der sogenannten Hortativformel, heißt es: „Damit man nun

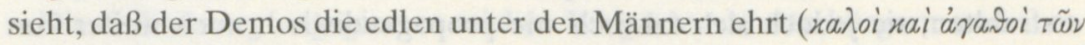

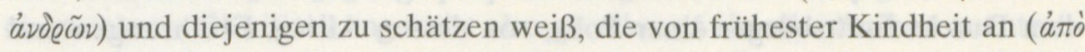

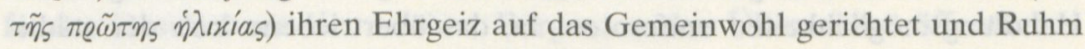

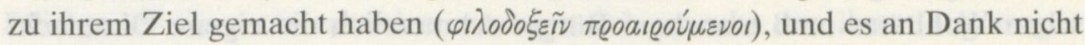
fehlen läßt, und damit alle anderen durch die Betrachtung der Ehren, die den Edlen vom Demos zuteil werden, zum Streben nach dem Schönsten moti-

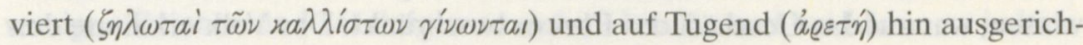
tet werden, und damit schließlich das Gemeinwesen daran aufblüht, daß alle im Streben nach Ruhm ermuntert sind, der Heimat stets etwas Gutes zu tun. " 55

Menas wird also geehrt, weil er in Wort und Tat unter Beweis gestellt hat-

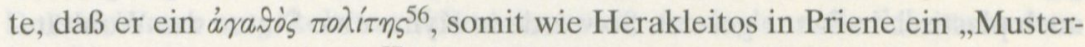
bild eines Bürgers" abgab. ${ }^{57}$ Neben der Erinnerung stiftenden Funktion wird zugleich die erzieherische Intention eines solchen Beschlusses deutlich formuliert. ${ }^{58}$ Neben den Heroenerzählungen der Dichter wurden den Ehrbezeugungen für verdiente Männer generell eine wichtige pädagogische Wirkung zugeschrieben, was insbesondere aus der Anklagerede des athenischen Honoratiors Lykurg gegen den Landesverräter Leokrates hervorgeht. Demnach bewahrten Dichtungen wie auch die Dekrete die Erinnerung an individuelle sittliche Größe und edles Ethos ( $\$ 100: \mu \varepsilon \gamma a \lambda$ a vermochten durch die Erzählung „der herrlichsten Vorbilder“ die Bürger zu belehren ( $\$ 100: \delta i \delta a ́ \sigma \varkappa \varepsilon ı)$. In der Vermittlung eines angemessenen politischen Ethos ergänzten sie nach Auffassung Lykurgs aufs Beste die Gesetze (§102): „In ihrer Knappheit belehren die Gesetze nicht (

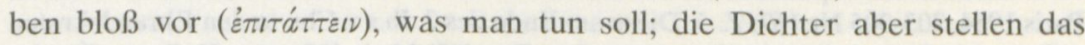

54 Hiermit ist gut zu vergleichen der Ehrenbeschluß für den Gymnasiarchen Lyson aus Xanthos von 196 v. Chr.: REG 109, 1996, 1 ff. = HGI 456.

55 IvSestos 1 = OGIS 339, 86-92.

56 So etwa in dem milesischen Dekret zu Ehren des Eirenias (165 v. Chr.): SEG 36,1046

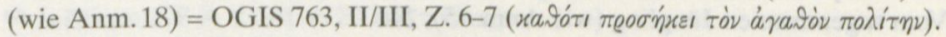

57 IvPriene 117 Z. 57 (Text s. Anm. 60).

58 S. den ausführlichen Kommentar in der Edition von Peter Frisch, Die Inschriften von Sestos und der thrakischen Chersones. Bonn 1980 [IvSestos], 14-29. 43-63. 


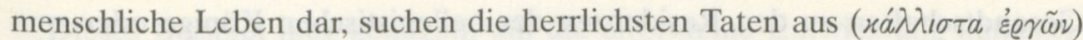
und leiten so die Menschen durch Erzählung und durch anschaulichen Beweis". 59 Genau dieses leisteten die Ehreninschriften für verdiente Männer einer Stadt. Die Dekrete legten den Lesern das ,schöne' politische und euergetische Wirken der Geehrten im Dienste ihrer Bürgerschaft anschaulich dar

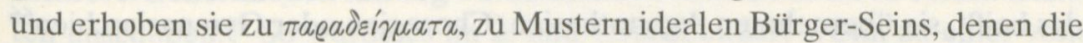
Mitbürger, die städtische Jugend und die Nachwelt nacheifern sollten. Besonders deutlich wird das im Lob auf Herakleitos von Priene gesagt: Er habe sein eigenes Leben der Jugend als schönstes Beispiel vor Augen gestellt, so wie die Erziehung die moralische Norm vorgebe. ${ }^{60}$

Ansonsten heben sich den Dekreten zufolge die Mitglieder wirklich führender Familien von anderen eher ,durchschnittlichen' Politikern vor allem dadurch ab, daß sie sich entweder allein, jedoch dann immer mit einem nachdrücklichen Verweis auf die Vorfahren und deren Verdienste ${ }^{61}$, oder zusammen mit dem Vater oder Bruder erfolgreich für die Belange der Stadt einsetzten. Aus Athen lassen sich als Beispiele hierzu die Ehrendekrete für prominente Politiker wie Lykurg (307/06), Phaidros von Sphettos (um 255/54) oder Eurykleides anführen (229): Sie alle agieren in der Tradition ihrer Väter und Vorfahren - im Phaidrosdekret heißt es ausdrücklich, er habe dieselbe Gesinnung wie seine Vorfahren ${ }^{62}$-, sie alle zeichnen sich durch herausragende politisch-diplomatische oder militärische Leistungen aus ${ }^{63}$, machen sich bei militärischen Konflikten mit anderen Städten, Bünden, Piraten und Barbaren verdient, bestreiten nicht zuletzt aus eigenen Mitteln langwierige

59 Vgl. Lyc. Leocr. 90-92. Während Lykurg in $§ 4$ den Verbotscharakter der Gesetze hervorhebt, deutet er - mit Blick auf sein richterliches Publikum - die Funktion der Gesetze in $\S 102$ um: als Aufforderung zur Verfolgung unpatriotischer ,Übeltäter .

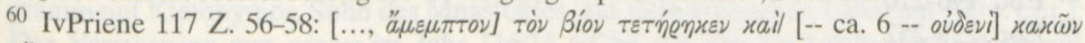

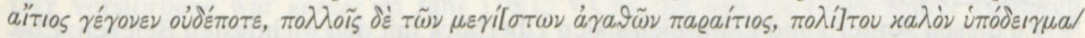

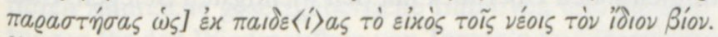

${ }^{61} \mathrm{Qua} \beta$, Honoratiorenschicht (wie Anm. 20), 42f. In einigen Fällen wurde die exklusive Stellung der Familie durch den Verweis auf eine lange Ahnenreihe besonders hervorgehoben s. etwa: SGDI 5656 (Grabinschrift des Heropythos von Chios mit 14 Vorfahren); SGDI 4859 (Grabinschrift des Klearchos von Kyrene, um 220 v. Chr.); vgl. auch das Dekret zu Ehren des Phaidros von Athen, u. Anm. 67 und 70.

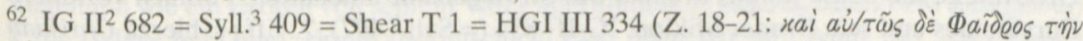

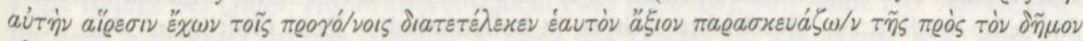
súvoias). Ebenso erwies sich Lyson aus Xanthos in seinem politischen Engagement als seiner Vorfahren würdig: Nachdem er sich bereits auf vielfältige Weise in den Dienst der Bürgerschaft gestellt hatte, übernahm er in Notzeiten für zwei Jahre das Amt des örtlichen Gymnasiarchen und sorgte für die erforderlich gewordene Instandsetzung und glanzvolle Ausschmückung der Institution: Philippe Gauthier, in: REG 109, 1996, 1-34 = HGI 456. Aus diesem Grund sind bereits in dem Ehrendekret für Lykurg von Athen die Ehren von dessen Urgroßvater und Großvater erwähnt: Syll. ${ }^{3}$ 326; Plut. Vit. Dec.or. $852 \mathrm{a}-\mathrm{e}$.

${ }^{63} \mathrm{Zu}$ den politischen Aktivitäten im militärischen und außenpolitischen Bereich: Quaß, Honoratiorenschicht (wie Anm. 20), 81-149. 
Gesandtschaften zu den Residenzen der hellenistischen Könige oder zum Senat in Rom und treten überdies in der Heimat als reiche Euergeten in Erscheinung: Als letztere setzen sie die städtischen Mauern instand, initiieren und finanzieren Bauvorhaben ${ }^{64}$ oder sorgen in Krisenzeiten für die notwendigen Getreidelieferungen ${ }^{65}$, kommen klaglos ihren Leiturgiepflichten nach, das heißt, sie übernehmen Agonothesien, Choregien oder Gymnasiarchien ${ }^{66}$ - und werden dafür, was kaum noch verwundert, mit nicht mehr überbietbaren städtischen Ehren bedacht, und zwar häufig mit allen zugleich: mit einem goldenen Kranz, mit einer Bronzestatue auf der Agora, mit der Speisung im Prytaneion für ihn und seine Nachkommen sowie mit einem permanenten Ehrensitz bei allen Festspielen. Bei Phaidros wird zudem erkennbar, daß er die eigene herausragende, von seinem Vater und Großvater begründete Stellung an seinen Sohn Thymochares weiterzugeben versuchte, indem er ihm bei dessen Agonothesie aushalf und unterstützte. ${ }^{67}$ Doch auch in anderen Städten der griechischen Welt gab es derartige Honoratioren, nur sind sie weniger bekannt, so etwa das Ehrendekret des Agathinos aus Arkesine, in dem drei Generationen verdienter Vorfahren aufgeführt werden. Darin heißt es: „Agathinos und der Urgroßvater des Agathinos, Kleophantos, und der Großvater Agathinos und der Vater Agathinos sind ehrenwerte und nach Ruhm strebende Männer für unser Volk (von Arkesine) gewesen und haben die Stadt und die Heiligtümer mit Weihgeschenken geschmückt. Agathinos, der Sohn des Agathinos, entschied sich dafür, die Tugend seiner Vorfahren weiter zu mehren. Deshalb war er Oberpriester der Athena Itonia und sorgte für alles übrige schön und ehrliebend, was die Prozession und das Opfer für die Götter betraf (...).“68

64 Ebd. 196-210.

65 Ebd. 229-252.

$66 \mathrm{Zu}$ diesen Ämtern und Leiturgien s. den Überblick mit den wichtigsten Belegen: Ebd. 270-303.

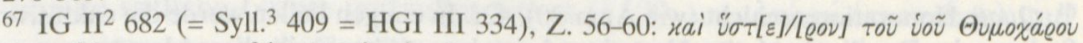

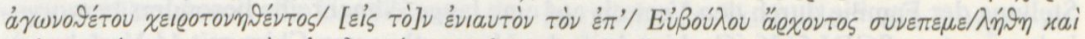

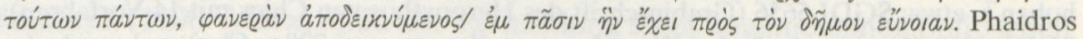
verweist im Dekret eigens auf die Leistungen seines Vaters Thymochares und seines Großvaters, die beide jeweils dreimal das Strategenamt innehatten. Ähnlich verfuhren Eurykleides und sein Bruder Mikion: IG II ${ }^{2} 834$ (=Syll. ${ }^{3}$ 497), Z. 5 ff.; s. hierzu Christian Habicht, Studien zur Geschichte Athens in hellenistischer Zeit. Göttingen 1982, $122 \mathrm{f}$. Dabei ist zu betonen, daß die Tradition des außerordentlichen politischen Engagements die Führungsstellung dieser Familien begründete - im Gegensatz zum alten Priesteradel (wie etwa den Eteobutaden, Keryken und Eumolpiden). Allgemein zur familiären Nachfolge in der politischen Führung der Städte: Quaß, Honoratiorenschicht (wie Anm. 20), 279f. (Hellenismus), 338ff. (Kaiserzeit).

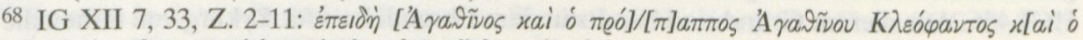

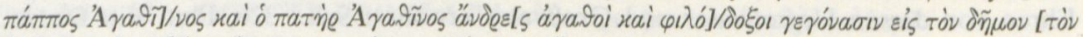

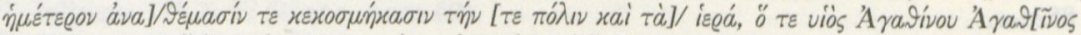

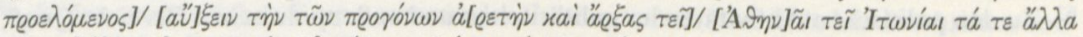

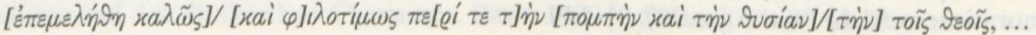


Dieses Beispiel mag genügen, um die allgemeine Entwicklung aufzuzeigen, die gerade in den kleineren Städten unverkennbar dahin ging, daß es einzelnen Politikern und ihren Familien zunehmend häufiger gelang, über längere Zeit, vielleicht über mehrere Jahrzehnte, mancherorts sogar über mehrere Generationen hinweg bestimmenden Einfluß in ihren Heimatstädten auszuüben. ${ }^{69}$ So wurde es im 2. und 1.Jahrhundert v. Chr. zu einer vom Volk vorbehaltlos akzeptierten Tatsache, daß die Söhne der Honoratioren in der Regel die soziale und politische Führungsstellung ihrer Väter übernahmen. Diese konnte auf der Bekleidung kostspieliger und prestigeträchtiger städtischer Ämter beruhen - wie im Fall der eponymen Stephanephoren in Milet, der Gymnasiarchen im thessalischen Pherai oder der Kosmoi im kretischen Lato pros Kamara - oder auf der exklusiven Ausübung von priesterlichen Aufgaben, die nach dem Tod der Amtsträger von deren Brüdern oder Söhnen übernommen wurden. ${ }^{70}$ In großen Städten kam es unter den altein-

${ }^{69}$ In manchen kleineren Städten gelang es sogar einem kleinen Kreis von Familien, die führenden städtischen Ämter für sich zu monopolisieren: So wurde beispielsweise im letzten Viertel des 2. Jh.s v. Chr. das oberste Gremium der kretischen Polis Lato pros Kamara (des heutigen Hagios Nikolaos), die fünf bis sieben jährlich amtierenden xó uo (un-

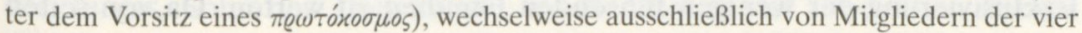
herrschenden aristokratischen Geschlechtern besetzt (Echanoreis, Aischeis, Hylleis und Synaneis). Die nicht bei der Besetzung der Kosmoi-Ämter zum Zuge gekommenen Familien durften statt dessen die rangmäßig nachgeordneten Gremien besetzen, die der

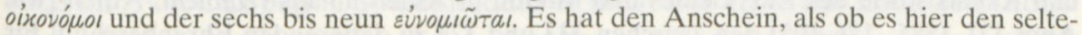
nen Fall einer stabilen, funktionierenden Aristokratie gegeben hätte. $\mathrm{Zu}$ den KosmoiInschriften der Periode von $122 / 21$ bis $111 / 10$ v. Chr. s. ausführlich: Martha W. Baldwin Bowsky, Portrait of a Polis: Lato pros Kamara (Crete) in the Late Second Century B.C., in Hesperia 58, 1989, 331-347. Einen aufschlußreichen Einblick in das umfassende Wirken der führenden Familien in einer kleinen See- und Handelsstadt gibt das Grabepigramm auf Kletonymos, Sohn des Mnastokles, aus dem kretischen Lato (um 100 v. Chr.): Der Verstorbene war xó $\mu \circ$ s im Jahr 116/15 v. Chr., tat sich im Laufe seiner Amtszeit durch zahlreiche gesetzgeberische Initativen und darüber hinaus durch großzügige Stiftungen für den Wiederaufbau von Tempeln und Herrichtung von Statuen hervor. Zudem wird er für seine Recherchen zur lokalen Geschichte gelobt. S. hierzu: Martha W. Baldwin Bowsky, Epigrams to an Elder Statesman and a Young Noble from Lato pros Kamara, in: Hesperia 58, 1989, 115-129, bes. 118-124 (Kletonymos).

70 Der Sprache der Dekrete zufolge hatte das jeweils nachfolgende Familienmitglied die

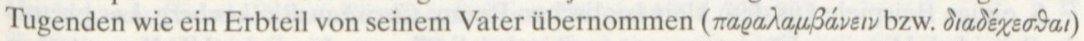
s. die Belege bei Quaß, Honoratiorenschicht (wie Anm.20), 46f. Anm.140. Als Beispiel für eine vom Vater ererbte Stellung s. etwa das Dekret für Dionysios, den Sohn des Melanthos, aus Iasos (IvIasos 90) aus dem Jahr 4-7 n. Chr., das den offenbar jung verstorbenen Priester des Agrippa Postumus preist als einen ,,allerbesten Mann geschmückt mit jeder Art von Arete, der dem Volk von Iasos Anlaß zu den größten Hoffnungen gab,

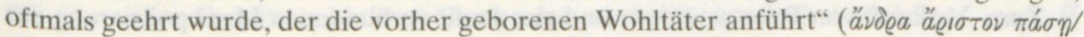

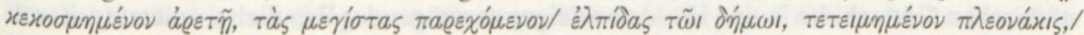

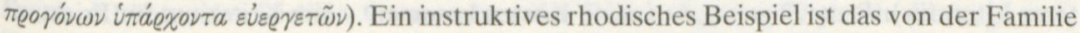
gestiftete Erinnerungsmonument für Herakleitos, Sohn des Pausanias, und seinen Sohn Apollodotos, auf dessen breiter Basis zwei Bronzestatuen aufgestellt waren: Amedeo Maiuri, Nuova silloge epigrafica di Rodi e Cos. Florenz 1925, Nr. 19, 29-32. Weitere Beispiele: Quaß, Honoratiorenschicht (wie Anm. 20), 142-145, 148, 155, 166. 
gesessenen Familien im Kampf um politischen Einfluß teilweise zu familiären Spezialisierungen. Die bereits erwähnte Familie des Atheners Phaidros war beispielsweise für ihre erfolgreichen Strategen bekannt: Der Vater wie auch der Großvater des Phaidros und Kallias von Sphettos hatten beide insgesamt dreimal die Strategie inne. Demgegenüber monopolisierte die Familie des Lykurg das auf der Akropolis beheimatete Priesteramt des Poseidon Erechtheus, während die Kerykes und Eumolpiden, weitere altehrwürdige athenische Geschlechter, in Eleusis die hohen Kultfunktionäre stellten - dem letzteren gehörte etwa der Daduche Themistokles an, Sohn des Daduchen Theophrastos. ${ }^{71}$ Und auch in vielen anderen Städten und Heiligtümern gehörten die Priester der bedeutsamsten Kulte alten, vornehmen Familien an ${ }^{72}$, so die Hekatepriester von Lagina, die Zeuspriester von Panamara, die Propheten des Didymeions von Milet oder die Priester der Athena Lindia auf Rhodos, später die Priester des Kaiserhauses.

Daß im 2. und 1. Jahrhundert v. Chr. mancherorts, vor allem im Südwesten der kleinasiatischen Küste und in der östlichen Ägäis, Priestertümer an die Höchstbietenden (teils auf Lebenszeit), verkauft' und die jährliche Wahl aufgegeben wurde 73 , ist als weiterer Beleg für die grundsätzliche Tendenz einer Exklusivierung der wenigen führenden Familien zu werten. Da von seiten

Für die Vorherrschaft eines Brüderpaares s. über die bekannten Beispiele des Phaidros und Kallias sowie des Eurykleides und Mikion in Athen hinaus (Habicht, Athen [wie Anm.17], 158f., 176-195) den zwischen 333 und 323 zu datierenden Ehrenbeschluß für Gorgos und Minnion aus Iasos, die Söhne des Theodotos (I.v.Iasos $30=$ Syll. $^{3} 307=$ SGDI

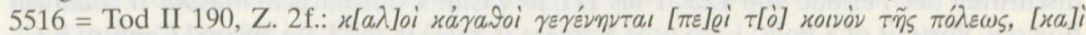

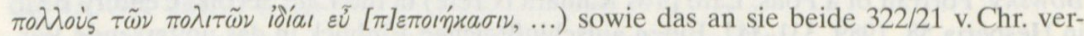
liehene Bürgerrecht der Stadt Samos (Syll. ${ }^{3} 312$ = SGDI $5698=$ IvIasos II T 50). S. des weiteren: Polykritos und Phyrson in Erythrai: IvErythrai 24f.; Timarchos und Herakleides in Milet: Quaß, Honoratiorenschicht (wie Anm.20), 105f., 209; Moschion und Athenopolis in Priene: IvPriene 107f. Xenophon und Kleonymos in Kos: Quaß, Honoratiorenschicht (wie Anm. 20), 151, 170

71 S. hierzu allgemein Kevin Clinton, The Sacred Officials of the Eleusinian Mysteries. Philadelphia 1974. Zu dem Ehrendekret für Themistokles aus dem Jahr 20/19 v. Chr., der in Z. 32-33 als ,an Vortrefflichkeit und vornehmer Herkunft hervorragend“ bezeichnet

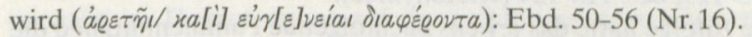

72 S. einige Beispiele aus dem kleinasiatischen Raum: Christian Blinkenberg, Les prêtres de Poseidon Hippios. Étude sur une inscription lindienne. Lindiaka VI. Kopenhagen 1937, 17f.; Michael Wörrle, Inschriften von Herakleia am Latmos II. Das Priestertum der Athena Latmia, in: Chiron 20, 1999, 19-58; Wolfgang Günther, „Unsterbliche Kränze“. Zur Selbstdarstellung milesischer Propheten in didymeischen Inschriftendenkmälern, in: Chiron 33, 2003, 448f.

73 Zum ,Verkauf' von Priestertümern und zur damit verbundenen Monopolisierung der städtischen Götterkulte in den Händen weniger vermögender Familien s. zuletzt (mit weiterer Literatur): Beate Dignas, ,Auf seine Kosten kommen`- Ein Kriterium für Priester? Zum Verkauf von Priestertümern im hellenistischen Kleinasien, in: Gudrun Heedemann/ Engelbert Winter (Hrsg.), Neue Forschungen zur Religionsgeschichte Kleinasiens. Elmar Schwertheim zum 60. Geburtstag gewidmet. Bonn 2003, 27-40; Hans-Ulrich Wiemer, Käufliche Priestertümer im hellenistischen Kos, in: Chiron 33, 2003, 263-310. 
der Bürgerschaft in der Regel nur die Kassenführung und nicht die Kultausübung kontrolliert wurde, boten die priesterlichen Ämter hinreichend Spielraum, sich aus der Menge der gewöhnlichen Bürger herauszuheben, beispielsweise durch großzügige Spenden von Opfertieren oder durch die Finanzierung der architektonischen Ausgestaltung und Ausschmückung der Heiligtümer ${ }^{74}$ : Im öffentlichen Vollzug der städtischen Opfer demonstrierten sie der als Kultgemeinschaft zusammengekommenen Bürgerschaft immer wieder aufs Neue ihre herausgehobene soziale Stellung und akkumulierten zugleich im Lauf der Zeit, sofern ein Kult dauerhaft der Obhut einer Familie unterstand, ein exklusives Ritualwissen darüber, wie man die Götter in der rechten Weise im Gebet anzurufen und ihnen zu opfern habe. Zudem hinderte die Bekleidung eines solchen Priesteramts die Mitglieder der vornehmen Familien nicht daran, auch zivile Ämter zu übernehmen und politisches Kapital aus der Priesterwürde zu schlagen. Ebenso war es auch für militärische Spezialisten üblich, ihr Kriegshandwerk mit politischen und religiösen Führungspositionen zu verbinden. ${ }^{75}$

Anschaulich wird das etwa in der Weihinschrift einer beim örtlichen Apollontempel etwa um 200 bis 175 v. Chr. von der Familie gestifteten Ehrenstatue des Teisias, Sohn des Theudamos, aus Kedreai in der rhodischen Peraia: Nicht nur in seiner eigentlichen Profession, in der militärischen Laufbahn, die ihn bis zum Strategenamt hinaufführte, war Teisias erfolgreich, sondern auch im zivilen Leben ${ }^{76}$ : So bekleidete er nicht nur eines der höchsten rhodischen Ämter, die Prytanie, sondern wurde auch von den Phylengenossen mit einem goldenen Kranz geehrt und hatte zudem das Amt des Apollonpriesters in Kedreai inne. Darüber hinaus war er ein herausragender Sportler, der bei mehreren städtischen Festspielen im Ringen und im Pankration siegte. Zusätzliches Ansehen verschaffte er sich durch die Übernahme der Agono-

74 Zum Aufgabenbereich der Priester s.: Kai Trampedach/Beate Dignas (Eds.), Practitioners of the Sacred. Greek Priests from Homer to Julian. Cambridge, Mass. 2007; vgl. (zur klassischen Zeit) Robert Garland, Priests and Power in Classical Athens, in: Mary Beard/John North (Eds.), Pagan Priests. Religion and Power in the Ancient World. London 1990, 75-91; Sara B. Aleshire, The Demos and the Priests, in: Robin Osborne/Simon Hornblower (Eds.), Ritual, Finance, Politics. Oxford 1994, 325-337.

75 Während die Akkumulierung öffentlicher Funktionen in hellenistischer Zeit allerorts zu beobachten ist, wurden diese in Athen seit dem Beginn des 4.Jh.s v. Chr. in der Regel voneinander getrennt wahrgenommen: Debra Hamel, The Separation of Political and Military Authority in Fourth Century Athens, in: Ancient History Bulletin 9/1, 1995, 25-39.

76 S. beispielhaft die politische Lebensleistung des Rhodiers Polykles, Sohn des Soses, der von seiner Familie im 1.Jh. v. Chr. geehrt wird. Die Inschrift verzeichnet sorgsam sämtliche militärischen (Hegemon, Stratege, Trierarch etc.) und zivilen Ämter (Gymnasiarch, Klerotes der Richter, Grammateus des Rates, Prytane, Phylarch, Chorege etc.) des Großvaters: Maiuri, Nuova Silloge (wie Anm.70), Nr.18, 19-29. Die Familie eines rhodischen Nauarchen aus dem 1.Jh. v. Chr. hat jüngst erörtert: Vassa Kontorini, La famille de l'admiral Damagoras de Rhodes. Contribution à la prosopographie et à l'histoire rhodiennes au 1er s. av. J.-C., in: Chiron 23, 1993, 83-97. 
thesie, der Leitung eines Festes. Ihren Reichtum und ihre Vorrangstellung brachte die Familie schließlich dadurch zum Ausdruck, daß sie eine Statue von dem Bildhauer Pythokritos anfertigen ließ, der offenbar ein damals berühmter Künstler war und durch seine Signatur auf mehreren anderen Statuenbasen bekannt ist. ${ }^{77}$

Als zweites Beispiel verweise ich auf einen Ehrenbeschluß für Orthagoras (aus dem 2. Jahrhundert), der dem lykischen Araxa entstammte. ${ }^{78}$ Dort heißt es unter anderem: „Als hervorragender Mann wie schon seine Vorfahren hatte er viele bedeutende Beweise seines Engagements gegenüber dem Volk seit früher Jugend abgelegt" ${ }^{\text {"79 }}$, als Kommandant des städtischen Aufgebots ( Krieg gegen den Tyrannen Eudemos, später in dem gegen die Termessier in der lykischen Reiterei jeweils, wie es ausdrücklich heißt, in vorderster Front

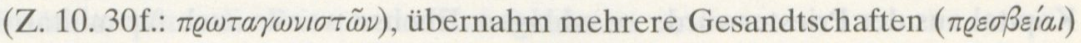
und Festgesandtschaften ( (¿eweía $)$ und bekleidete das oberste lokale Priesteramt. ${ }^{80}$ Zahlreiche Dekrete mit ähnlich ausführlicher Auflistung der politischen, religiösen und militärischen, jedenfalls immer der Öffentlichkeit nutzenstiftenden Leistungen des Geehrten ließen sich leicht anführen.

\section{Gymnasiale Bildung als Voraussetzung für das politische Wirken der Honoratioren}

Von klein auf waren die Söhne der Honoratioren in die vielfältigen religiösen und politischen Rituale ihrer Familie und der Gemeinde eingebunden. Im Gymnasion hielten sie sich bereits als Knaben auf, dort wurden sie vor allem

77 IvRhod. Per 553. Die Inschrift stammt von der Basis einer Ehrenstatue des Mannes

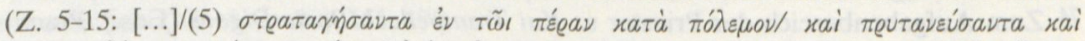

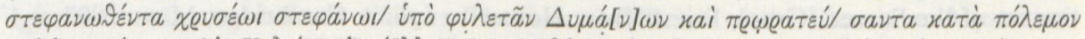

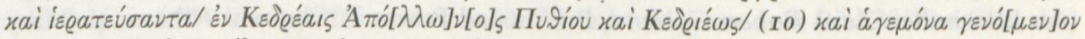

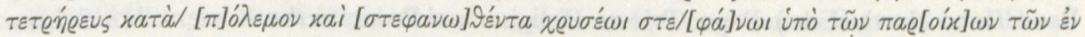

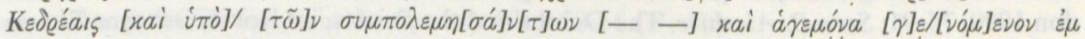

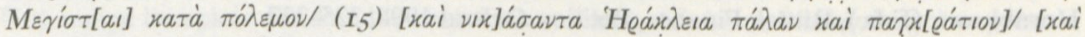

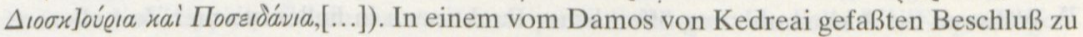
Ehren des Teisias wird dieser mit goldenem Kranz, Bronzebild und Prohedrie geehrt (IvRhod. Per 552). Belege für die Tätigkeit des in Z. 20 genannten Bildhauers Pythokritos: IvRhod. Per. Kommentar zu Nr.553 p. 134.

78 George E. Bean, Notes and Inscriptions from Lycia, in: JHS 68, 1948, 46-56 (Nr.11) = SEG $18,570=$ HGI III 479.

79 Das Ehrendekret, das ausführlich die für die Polis Araxa bedeutsamen Taten des Orthagoras referiert und ab der Zeile 77 abbricht, wird mit diesem Einleitungssatz be-

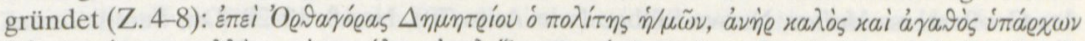

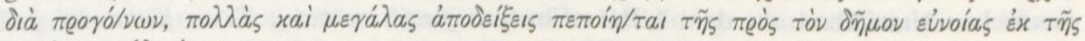

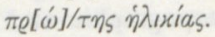

80 IGR III 563 = OGIS 556. 


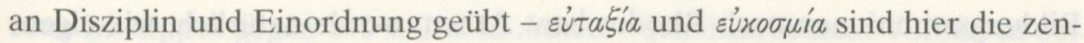
tralen Begriffe. Durch periodisch wiederkehrende Wettbewerbe vor allem in den sportlichen Disziplinen wurden die Heranwachsenden zu Übung

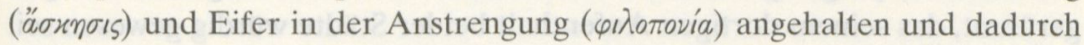
maßgeblich ihr Charakter und ein kompetitives Ethos ausgebildet. ${ }^{81}$ Auf allen Feldern des Wissens und der Fertigkeiten maß man sich miteinander, überall wurde der Beste ermittelt.

Ein für die Erörterung der Honoratiorenerziehung besonders sprechendes und zugleich ein für die späthellenistische Zeit charakteristisches Zeugnis ist das Dekret zu Ehren des jungen Honoratiorensohns Melanion von Iasos. ${ }^{82}$

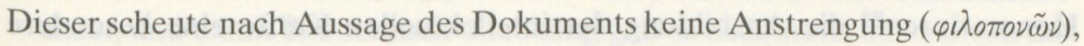

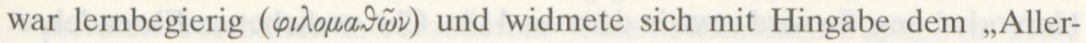
schönsten“; neben den altersgemäßen Fächern hatte er sogar Philosophie

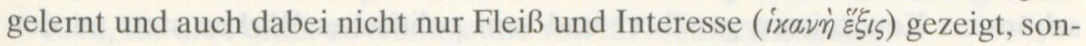
dern auch rasche Fortschritte gemacht (теокот $)$ ). Vollgültig verkörperte Me-

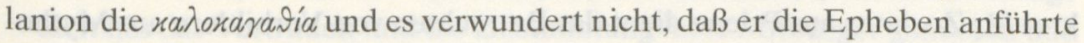
und seinen Vater bei der Ausübung von dessen Gymnasiarchenamt tatkräf-

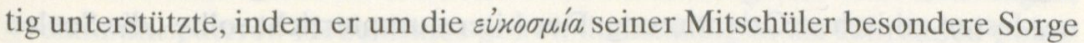
trug. Die Erziehung erfolgte hier somit nicht in einem exklusiven privaten Raum, sondern in aller Öffentlichkeit. Die herausragende Tugend wurde von den Bürgern mitangesehen und mitertragen.

Für den weiteren Verlauf der Erziehung, für das auswärtige Studium, sind die Dekrete für Menippos und Polemaios von Kolophon aufschlußreich. Sie geben einen Einblick in den Bildungsgang zweier Honoratioren, der in anderen weniger ausführlichen städtischen Beschlüssen zu Ehren verdienter Männer in der Regel nicht zur Erwähnung kommt: Diese beiden führenden Politiker aus Kolophon verlassen nach einigen Jahren der Ausbildung vor Ort das heimische Gymnasion, das für ihre weitreichenden Ambitionen und vielfältigen Interessen zu eng geworden ist, und gehen für ihre weiterreichenden

${ }^{81}$ So wird ausdrücklich formuliert in: IvSestos 1 = OGIS 339 Z. 67-72. Ein weiteres bezeichnendes Beispiel für die Bildungsanstrengungen der städtischen Führungsschichten im 1.Jh. v. Chr. ist die Biographie des Iollas, Sohn des Iollas, aus Sardis: Er ging bei Antiochos von Askalon in die Schule, der zwischen 86 bis 69 v. Chr. der Akademie vorstand. Seine Heimatstadt zeichnete zwischen 60/50 v. Chr. den gebildeten Mann für seinen lebenslangen Dienst an der Polis (Übernahme mehrerer Gesandtschaften, erfolgreiche Bewältigung verschiedener Kämpfe und Prozesse, Bekleidung der höchsten städtischen Ämter, Übernahme der Agonothesie der Panathenaia und Eumeneia, Priester der Roma, Veranstaltung von Opfern und Gastmählern, Geldspenden) mit einer außergewöhnlichen Fülle an Ehrungen aus (mit mehreren Kränzen, einer vergoldeten Statue, einer vergoldeten Kolossalstatue, einer vergoldeten Reiterstatue, vier weiteren Bronzeund drei Marmorbildern sowie vier Porträts!): IvSardis 27 (mit Taf. 9) mit den Erläuterungen von: Christian Habicht, Der Akademiker Iollas von Sardis, in: ZPE 74, 1988, 215-218.

${ }^{82}$ IvIasos 98 = GIBM 925 b. 
Bildungsambitionen nach Rhodos bzw. Athen, wo sie natürlich, wie eigens hervorgehoben wird, Unterricht bei den besten Lehrern erhalten. Polemaios scheint dabei jünger gewesen zu sein, an ihm wird nur sein gutes Betragen gerühmt, das seinem dortigen Aufenthalt beider Städte würdig gewesen sei. Demgegenüber wird Menippos mit Kranz und Bürgerrecht geehrt und so seiner herausragenden Persönlichkeit das erwartet gute Zeugnis ausgestellt (

Neben der Vervollkommnung der sportlichen Fähigkeiten und der Unterweisung im Umgang mit den Waffen erfährt in diesen „langen“, den Weg des öffentlichen Wirkens nachzeichnenden Dekreten zu Ehren der städtischen Honoratioren ${ }^{84}$ die Ausbildung der intellektuellen Kräfte eine besondere Hervorhebung: So wird etwa in dem um 110 v. Chr. verliehenen Ehrendekret für Polemaios von Kolophon davon berichtet, daß ,er seine Seele mit den schönsten Kenntnissen genährt" und sein politisches Wirken stets an den „herrlichsten Dingen“ ( $\alpha^{\prime} \lambda_{\lambda} \iota_{\sigma \tau} \tau$ ) ausgerichtet habe (col. I). Laut dem Dekret für Zosimos aus Priene dient das Betrachten von Vorbildern aus Mythologie und Geschichte eben diesem Zweck, der Vermittlung von $\varkappa a ́ \lambda \lambda ı \tau a$, einer festen ethischen Orientierung: Der Literaturunterricht sollte „die Seelen (der Schüler) zu tugendhaftem Handeln und Verständnis für menschliches Leid führen" 85 , so daß die Honoratiorensöhne bereits als Jugendliche - wie

83 Unverzichtbar zur historischen Einordnung dieser beiden Dekrete: Robert, Claros I (wie Anm. 19); Lehmann, Römischer Tod (wie Anm. 19). Die Darstellung des Lebensweges im ersten Ehrendekret für Apollonios von Metropolis (Boris Dreyer/Helmut Engelmann, Die Inschriften von Metropolis I: Die Dekrete für Apollonios. Städtische Politik unter den Attaliden und im Konflikt zwischen Aristonikos und Rom. Bonn 2003) ähnelt dem des Polemaios oder Menippos von Kolophon: Einer angesehenen Familie angehörend - darauf weist die Angabe des Namens seines Großvaters Andron hin - wächst er

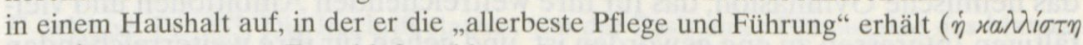
$a ́ \gamma \omega \gamma \eta \dot{)}$. Aus eigenem Entschluß wählt er den beschwerlichen Weg: „sich in allem um

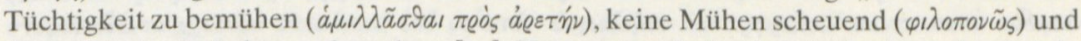
diszipliniert sein Leben zu bestehen, [...]. Von seinem Aufenthalt in der Fremde zurückgekehrt ging er daran, sich in der Öffentlichkeit auf nützliche Weise zu betätigen, und kam bei den Leistungen für die Allgemeinheit seiner Pflicht nach, wobei er dazu ohne Zögern bereit war“ (IvMetropolis I, B: Dekret der Nebenseite, Z. $4 \mathrm{ff}$.).

${ }^{84} \mathrm{Zu}$ diesen seit dem 3. Jh. v. Chr. auftretenden, biographischen' Inschriften s. Robert M. Errington, Biographie in hellenistischen Inschriften, in: Konrad Vössing (Hrsg.), Biographie und Prosopographie. Internationales Kolloquium zum 65. Geburtstag von Anthony R. Birley, Düsseldorf. Stuttgart 2005, 13-28. Grundlegend immer noch Rosen, Ehrendekrete (wie Anm.33).

85 IvPriene 112, Z. $73 \mathrm{ff} .:$,[...] und (er soll bestimmen) einen Aufseher, der zugleich bei den Epheben als Grammatiker für die (Wissensgebiete) aus der Philologie tätig ist, mittels (beider Lehrer) wollte er einerseits die Körper (der Jugend) unempfindlich machen, andererseits die Seelen (der Jugend) zu Tüchtigkeit und zur Empfindung menschlichen

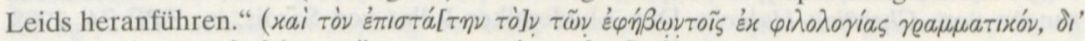

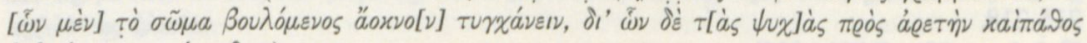

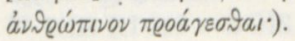


etwa Menippos gegen 140 v. Chr. in Athen - „ein herrlichstes Vorbild in der Lebensführung und in ihrer Bildung darstellten“. 86

\section{Einige Schlußfolgerungen}

Möchte man ein Resümee zu diesem Überblick über die Herrschaft der Honoratioren in den hellenistischen Städten ziehen, so sind meines Erachtens sechs Merkmale für diese „demokratischen Oligarchen“ kennzeichnend ${ }^{87}$ :

- Erstens waren sie Rentiers, mithin: Grund-, Sklaven-, Vieh- und Hausbesitzer, und damit ökonomisch unabhängig. Das bedeutete, daß sie von den privaten Geschäften in besonderem Maße abkömmlich waren. Auf diese Weise war es ihnen möglich, um die Formulierung Max Webers zu gebrauchen, für die Politik zu leben, ohne von ihr leben zu müssen.

- Zweitens besaßen sie ein so hohes soziales Ansehen, daß sie über lange Zeit hin das Vertrauen und die Zustimmung ihrer Mitbürger genossen und bei formell bestehender Demokratie zunächst aufgrund ihrer Leistungen, dann im späteren Hellenismus gewohnheitsmäßig in die führenden politischen Ämter gewählt wurden.

- Drittens spielten sie durch ihre politisches und soziales Wirken - als Diplomaten, als Amtsträger und als Euergeten - eine führende Rolle in den Städten, ohne daß sich daraus eine neue Herrschaftsform entwickelte. Zentraler Bezugspunkt und Quelle des Prestiges blieb für jeden Honoratioren die öffentliche Tätigkeit für die Bürgerschaft - und nicht die private Lebensführung.

- Viertens: Das soziale und politische Wirken in und für die Gemeinschaft geschah einerseits aus traditioneller Verbundenheit und Solidarität mit der Heimatstadt (Eüvoıa). Andererseits befanden sich die Honoratioren untereinander im beständigen Wettbewerb um den an Ehre und Ruhm

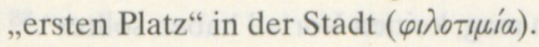

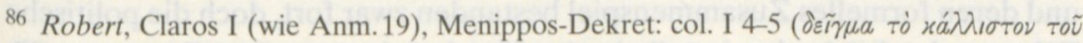

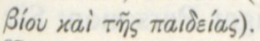

87 Vgl. Max Webers Definition von Honoratioren (Wirtschaft und Gesellschaft. 5. Aufl. Tübingen 1980, 170 [Kap. III § 20]): „Honoratioren sollen solche Personen heißen, welche 1. kraft ihrer ökonomischen Lage imstande sind, kontinuierlich nebenberuflich in einem Verband leitend und verwaltend ohne Entgelt oder gegen nominalen oder EhrenEntgelt tätig zu sein, und welche 2. eine, gleichviel worauf beruhende, soziale Schätzung derart genießen, daß sie die Chance haben, bei formaler unmittelbarer Demokratie kraft Vertrauens der Genossen zunächst freiwillig, schließlich traditional, die Ämter inne zu haben. 3. Unbedingte Voraussetzung der Honoratiorenstellung in dieser primären Bedeutung: für die Politik leben zu können, ohne von ihr leben zu müssen, ist ein spezieller Grad von ,Abkömmlichkeit' aus den eigenen privaten Geschäften. Diesen besitzen im Höchstmaß: Renter aller Art: Grund-, Sklaven-, Vieh-, Haus-, Wertpapier-Rentner“. 
- Fünftens: Da die Städte in hellenistischer Zeit auf gute Beziehungen zu den Königen und Römern angewiesen waren, gewannen die persönlichen Fähigkeiten, Kenntnisse und Verbindungen der städtischen Elite stark an Bedeutung. Die Politik wurde, was als Tendenz seit dem 4. Jahrhundert v. Chr. zu beobachten ist, zunehmend exklusiver, das heißt: zur Sache einiger weniger Einzelpersonen. Die neuartigen Bedürfnisse der Bürgerschaften (Gymnasion, Feste, Schule und Bildung,) bei im wesentlichen unveränderten städtischen Einkünften führte dazu, daß Ämter wie die Gymnasiarchie, Agonothesie oder Agoranomie in wachsendem Maße mit leiturgischen Leistungen verbunden wurden.

- Und sechstens: Der Demos wie überhaupt das politische Engagement wurde den herausgehobenen Bürgern ein Mittel zum Zweck für ihren Ehrgeiz, der „Beste“ oder „Erste“ in der Stadt zu sein. Sie alle hatten kein wirkliches Interesse daran, ihren Einfluß und ihre Machtstellung mit anderen zu teilen. So sehr die herausgehobenen ,Wenigen' persönlich auf Distinktion aus waren, so gering waren ihre Versuche, eine eigene, für sich abgeschlossene Klasse zu bilden, die sich vom Demos absetzte und abgrenzte.

Den Fortgang und Endpunkt dieser Entwicklung einer Aristokratisierung der politischen Führung durch wenige Familien, ohne daß diese jemals gänzlich die legitimatorischen Bindungen an die Bürgerschaft gelöst hätten, markiert eine Bemerkung des kaiserzeitlichen Honoratioren und berühmten Redners Dion von Prusa, der in seiner zweiten Rede vor den Tarsiern $(34,1)$ sagt: „Wie mir wohl bekannt ist, ist es bei Euch wie auch anderswo üblich, daß die Bürger auf die Rednerbühne treten und Ratschläge erteilen; natür-

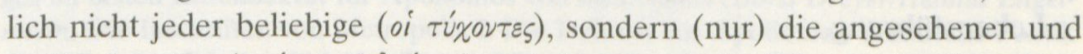

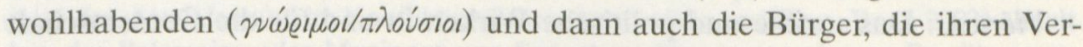
pflichtungen dem Gemeinwesen gegenüber besonders gut nachgekommen

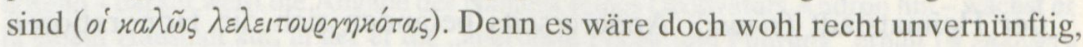
wenn ihr vom Besitz der Reichen euren Anteil bekämet, von ihrer Einsicht aber, wie auch immer sie geartet sein mag, keinen Vorteil haben solltet" 88 In der Kaiserzeit fand der Prozeß der Exklusivierung und Aristokratisierung seinen Abschluß. Die altehrwürdig gewordenen demokratischen Institutionen und deren formelles Zusammenspiel bestanden zwar fort, doch die politische Führung der Städte lag jeweils in der Hand einiger weniger Personen: Sie

88 In der Einleitung zu den an die Mitglieder der städtischen Führungsschicht gerichteten Ratschlägen (mor. 798b) setzt Plutarch eine vornehme Herkunft als selbstverständlich für jede Art von politischer Betätigung voraus: „Wenn du bemerkst, daß bei Dir ein Verlangen danach vorhanden ist, wie es Deiner hohen Geburt angemessen ist ( $\dot{a} \xi i \omega \varsigma \tau \tilde{\eta} \zeta$

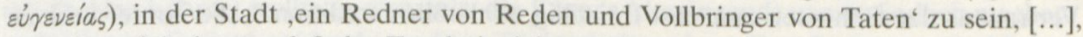
dann bete ich darum, daß das Ergebnis deinem Einsatz und meiner Bereitschaft angemessen ist". S. hierzu die grundsätzlichen Bemerkungen von: Helmut Halfmann, Die Selbstverwaltung der kaiserzeitlichen Polis in Plutarchs Schrift ,Praecepta gerendae rei publicae', in: Chiron 32, 2002, 83-96. 
war nunmehr endgültig zum Vorrecht der vermögenden und vornehmen Männer und ihrer Familien geworden, die zum Teil die Stellung lokaler Monarchen einnahmen. ${ }^{89}$ Die Fortsetzung ihrer informellen Herrschaft durch die Nachkommen wird als selbstverständlich betrachtet. An die Stelle der ruhmreichen Vergangenheit der Polis als des maßgeblichen Ausgangspunkts und Maßstabs des Handelns traten die Leistungen der Vorfahren. Mit diesen wetteiferten die „Ersten“ der Städte (oi $\pi \varrho \tilde{\omega} \tau o$ ) - das wird in der Kaiserzeit erstmals auch in den Inschriften formuliert. ${ }^{90}$

89 Deren gleichsam monarchische Stellung hebt insbesondere Paul Veyne, Le pain (wie Anm. 43), 310-327, hervor.

90 Die Belege für diesen imaginierten Agon mit den Ahnen finden sich bei: Michael Wörrle, Stadt und Fest im kaiserzeitlichen Kleinasien. Studien zu einer agonistischen Stiftung aus Oinoanda. München 1988, 56f. Dieser Wandel in der Sprache der Dekrete läßt sich mit der Orientierung und Nachahmung der politischen Kultur der römischen Senatsaristokratie erklären. 